\title{
四苯乙烯衍生物的应用研究进展
}

\author{
李宗植 ${ }^{a}$ 霍延平*,,$b$ 阳香华 ${ }^{a}$ 籍少敏 ${ }^{a}$ \\ $\left({ }^{a}\right.$ 广东工业大学轻工化工学院 广州 510006) \\ $\left({ }^{b}\right.$ 中国科学院上海有机化学研究所 有机氟化学中国科学院重点实验室 上海 200032)
}

\begin{abstract}
摘要 四苯乙烯衍生物因其分子内含有较大的共轭体系, 表现出许多独特的光电性能及生物活性, 在光电材料、生物 成像等诸多领域具有广泛的应用前景. 该类化合物具有合成简便、易功能化以及聚集诱导发光效应明显等优点，近年 来吸引了越来越多科学家的注意, 在多个研究领域均获得了突破性的进展. 综述了四苯乙烯衍生物在化学传感、生物 探针、有机发光二极管等领域的研究进展, 并对其发展趋势作了展望.
\end{abstract}

关键词＼cjkstart四苯乙烯; 聚集诱导发光; 化学传感; 生物探针; 有机发光二极管

\section{Progress on Research and Application of Tetraphenylethene Derivatives}

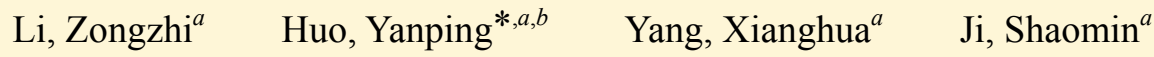 \\ ( ${ }^{a}$ School of Chemical Engineering and Light Industry, Guangdong University of Technology, Guangzhou 510006) \\ $\left({ }^{b}\right.$ Key Laboratory of Organofluorine Chemistry, Shanghai Institute of Organic Cheimstry, \\ Chinese Academy of Sciences, Shanghai 200032)
}

\begin{abstract}
Tetraphenylethene derivatives display unique optical and/or electrical properties and biological activity due to their large $\pi$-conjugated system, endowing their broad applications in optoelectronic materials, bio-imaging and other areas. Such compounds are facile to synthesize, easy to functionalize and have obvious aggregation induced emission (AIE) effect, thus attracted increasing more attentions and get tremendous development in the past dacades. The recent progress in research of tetraphenylethene derivatives in chemical sensing, biological probes, organic light emitting diodes (OLEDs) and relating areas is reviewed, and its development trend is briefly prospected.
\end{abstract}

Keywords tetraphenylethene; obvious aggregation induced emission; chemical sensing; biological probes; organic light emitting diodes

大多数荧光化合物在稀溶液中具有较高的荧光量 子产率, 而在聚集状态下荧光减弱甚至猝灭, 这就是聚 集诱导猝灭(Aggregation-caused quench, ACQ) 效应 ${ }^{[1 \sim 3]}$, 该效应很大程度限制了苂光化合物的实际应用范围。 2001 年, 唐本忠课题组 ${ }^{[4,5]}$ 发现了聚集诱导发光(Aggregation-induced emission, AIE)现象, 引起了科学界的广 泛关注 ${ }^{[6 \sim 16]}$. 具有 AIE 效应的材料在稀溶液中发光很 弱, 但在聚集状态下荧光大大增强, 此性质可以解决 ACQ 效应导致的荧光材料应用限制, 对固体荧光材料 的构建及其应用具有重要意义.

四苯乙烯(Tetraphenylethene, TPE)具有能自由旋转
的外围苯环的螺旋桨形结构, 是一种典型的 AIE 苂光发 光团, 其衍生物因发光性能优良、官能团容易修饰等优 点而被广泛地应用于合成. 近年来, 四苯乙烯衍生物在 化学传感、生物传感和有机发光二极管(organic light emitting diodes, OLEDs)等领域的应用取得了许多重要 的研究成果 ${ }^{[17 \sim 29]}$. 其中: (1)在化学传感领域中大量具有 高选择性、低检测限等优点的苂光探针被应用于离子、 爆炸物检测; (2)在生物传感方面, 研究者们开发了大量 能够与 DNA、硫醇等生物分子特异性结合、并能对其 中某些物质在生物体内的含量进行实时监控的苂光探 针, 其在生物成像、药物释放等医学检测中的应用对医

*E-mail: organicteacherhuo@126.com

Received April 11, 2016; revised May 18, 2016; published online June 20, 2016.

Project supported by the National Natural Science Foundation of China (Nos. 21172047, 21372051, 61671162) and the Science and Technology Planning Project of Guangdong Province (No. 2016A010103031).

国家自然科学基金(Nos. 21172047, 21372051, 61671162)、广东省科技计划(No. 2016A010103031)资助项目. 
疗诊断与治疗也具有重要意义; (3)在光电功能材料方 面, 研究者们利用具有高固态发光效率的 TPE 衍生物作 为发光层制作了大量发光性能优良的非掺杂 OLED 器 件, 为设计高效率、长寿命的 OLED 发光器件提供了新 途径. 结合近年来国内外对 TPE 衍生物的研究现状, 本 文按应用领域分类, 综述了四苯乙烯衍生物在化学传 感、生物传感以及 OLED 器件等领域的研究与进展.

\section{1 化学传感}

\section{1 离子检测}

近年来, 重金属污染已严重威胁到了人类的生活与 健康, 发展能选择性检测特定重金属的方法, 对重金属 污染的预防与治理意义重大. 2014 年, Khandare 等 ${ }^{[30]}$ 设 计合成了选择性检测 $\mathrm{Pb}^{2+}$ 的荧光探针 TPE 衍生物 1 , 其 发光机理是 1 与 $\mathrm{Pb}^{2+}$ 配位形成难溶的 $\mathrm{Pb}$-TPE 复合物, 进而触发其聚集诱导发光, 该探针对 $\mathrm{Pb}^{2+}$ 的检测效率很 高, 其检测限可达 $4.83 \times 10^{-8} \mathrm{~mol} / \mathrm{L}$.<smiles>O=P(O)(O)Oc1ccc(C(=C(c2ccccc2)c2ccccc2)c2ccccc2)cc1</smiles>

1

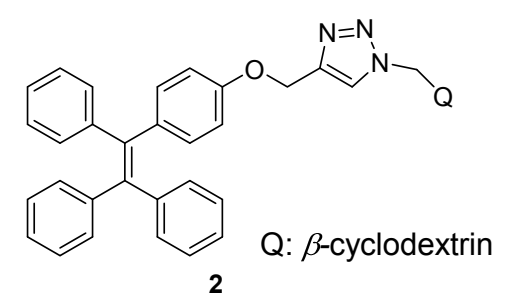

2

Wang 等 ${ }^{[31]}$ 通过点击化学方法合成了化合物 2 , 它 以 TPE 作为发光基元、三唑作为桥联基团、环糊精 (cyclodextrin, CD)作为亲水部分. 其三唑桥梁和 $\mathrm{CD}$ 基 团共同提供了与 $\mathrm{Cd}^{2+}$ 结合的位点, 使得 2 在中性溶液环 境中能高选择性地与 $\mathrm{Cd}^{2+}$ 结合形成复合物而聚集诱导 发光, 从而可作为一种在中性环境下检测 $\mathrm{Cd}^{2+}$ 的苂光 探针, 其最低检测限可达 $0.01 \mu \mathrm{mol} / \mathrm{L}$. 此外, 化合物 $\mathbf{2}$ 还具有良好的分子结合能力及生物相容性, 有望应用于 生物探针.

Shao 等 ${ }^{[32]}$ 成功研制了一种能够灵敏地检测 $\mathrm{Ag}^{+}$的 荧光探针, 即 TPE 衍生物 3 , 其最低检测限为 $8.74 \times$ $10^{-7} \mathrm{~mol} / \mathrm{L}$. 由于 $\mathrm{Ag}^{+}$具有很强的亲电性和亲硫性, 使 得 3 对 $\mathrm{Ag}^{+}$具有很高的离子选择性和检测灵敏度, 该课 题组通过核磁滴定和动态光散射(DLS)谱验证了其荧光 传感的选择性是由于化合物 $\mathbf{3}$ 与 $\mathrm{Ag}^{+}$在水溶液中结合而
产生的 AIE 效应.<smiles>CN(C)C(=S)SCCCOc1ccc(C(=C(c2ccc(OCCCSC(=S)N(C)C)cc2)c2ccc(OCCCSC(=S)N(C)C)cc2)c2ccc(OCCCSC(=S)N(C)C)cc2)cc1</smiles>

Yuan 等 ${ }^{[33]}$ 设计合成了共轭的 TPE 衍生物 4, 并把它 附在高定向热解石墨(highly oriented pyrolytic graphite, $\mathrm{HOPG}$ )表面, 形成了一种可以通过输出苂光信号来检测 $\mathrm{Zn}^{2+}$ 含量的自组装单层膜 (self-assembled monolayer, $\mathrm{SAM}$ ). 当引入 $\mathrm{Zn}^{2+}$ 时, TPE 衍生物 $\mathbf{4}$ 在水溶液中会发生 苂光增强, 而 SAM 却发生荧光猝灭现象. 通过使用高 分辨率的扫描隧道电子显微镜(scanning tunneling microscopy, STM)在空气/HOPG 界面分别观察 $\mathrm{Zn}^{2+}$ 加入 前后的 SAM, 并对比 4/HOPG 和 4/载玻片对 $\mathrm{Zn}^{2+}$ 的苂 光效应，结果表明：导致其苂光响应随着 SAM 结构变 化而变化的主要因素是以下三种作用力: 共轭 TPE中心 之间的 $\pi-\pi$ 相互作用、1,4-二甲氧丁基链间的范德华力 和金属-配体之间的相互作用.

焦磷酸根离子 $(\mathrm{PPi})$ 在人体的生化反应中发挥着重 要作用, 如 ATP 水解、DNA 聚合等. 2014 年, $\mathrm{Li}$ 等 ${ }^{[34]}$ 报 道了一种能选择性检测 PPi 的 TPE 衍生物 $\mathbf{5}$, 该化合物 即使在其它离子存在时, 也能高选择性地与 PPi 作用, 使化合物 5 的分子内苯环旋转受限, 从而聚集诱导发出 强烈荧光，其检测下限低达 $22.8 \mathrm{nmol} / \mathrm{L}$.

\section{2 爆炸物检测}

易爆物具有危险性大、破坏力强和种类繁多等特点, 因此, 靶向检测易爆物的荧光传感体系研究关系到人类 生命、财产安全, 意义重大, 而 TPE 衍生物在爆炸物检 测方面具有巨大潜能 ${ }^{[35,36]}$. Ullrich 等 ${ }^{[37]}$ 用微波加热法在 镍催化下合成了两种带有 TPE 侧链的具有 AIE 效应的 新型共轭聚合物 6, 即 PCzTPE 0.5 和 PCzTPE. 由于 TPE 侧链的存在, 使得 PCzTPE 0.5 在 $\mathrm{H}_{2} \mathrm{O}-\mathrm{THF}(V: V=1$ : 9)溶液中因 AIE 效应而具有的光致发光强度比其在纯 THF 溶液中的高出 35 倍. 通过 PCzTPE 0.5 对硝基爆炸 物的光致发光 PL 猝灭实验表明: 随着 1,3,5-三硝基苯 (TNB) 的加入, PCzTPE 0.5 在 $\mathrm{H}_{2} \mathrm{O}-\mathrm{THF}(V: V=1: 9)$ 溶 液中发生了明显的苂光猝灭(Stern-Volmer 方程的最大猝 灭常数为 $\left.1.26 \times 10^{-6} \mathrm{~L} / \mathrm{mol}\right)$. 同时, 涂覆有这两种聚合 物的检测试纸也会随着 TNB 的加入(气态和固态 TNB) 而引起苂光猝灭, 表明了聚合物 6 有望应用于制作检测 $\mathrm{TNB}$ 爆炸物的固态传感器. 
<smiles>[CH]OC(=O)c1cc(OCCCCOc2ccc(C(=C(c3ccccc3)c3ccc(OCCCCOc4cc(C(=O)O)nc(C(=O)OC)c4)cc3)c3ccccc3)cc2)cc(C(=O)O)n1</smiles>
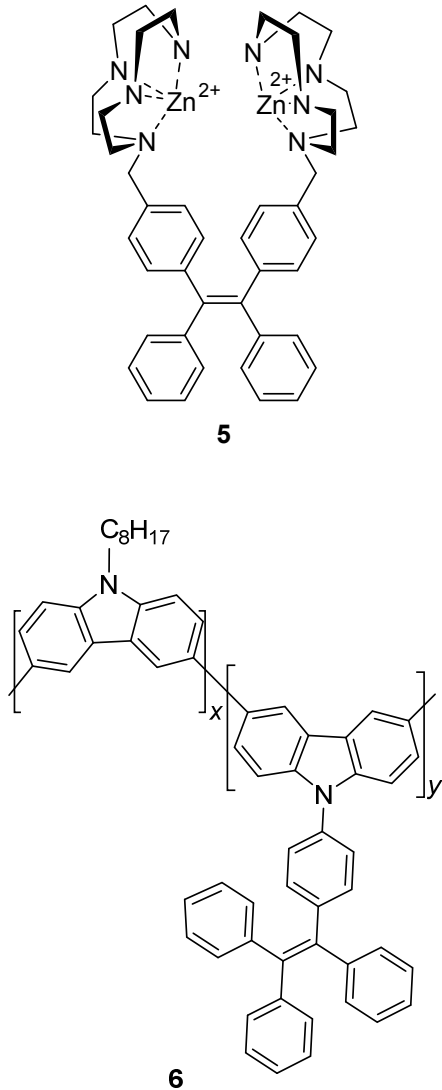

PCzTPE0.5: $x=y=0.5$

PCzTPE: $x=0, y=1$

2015 年, Zhou 等 ${ }^{[38]}$ 报道了三种能够在水溶液中检 测爆炸物的 TPE 衍生共轭聚合物 7,8 和 9. 这些聚合物 具有良好的热稳定性(分解温度高达 $406 \sim 482{ }^{\circ} \mathrm{C}$ ), 在 溶液状态下呈弱苂光, 在聚集状态下由于非辐射衰变途 径受阻而导致苂光增强(即 AIE 效应). 在水性介质中, 爆炸物 2,4,6-三硝基苯酚(TNP)能有效地使聚集状态下 的聚合物 7, 8 和 9 发生荧光猝灭, 猝灭常数 $K_{\mathrm{SV}}$ 值高达 $11830 \mathrm{~L} / \mathrm{mol}$, 表明这些聚合物也可以应用于爆炸物的 检测.

$\mathrm{Xu}$ 等 ${ }^{[39]}$ 通过硅氢化的方法, 将 TPE 单元接枝到笼 型聚倍半硅氧烷(polyhedral oligomeric silsesquioxane, POSS)上, 成功合成了两种树枝状的新型纳米杂化材料 10 和 11. 这两种化合物均具有典型的 AIE 效应和良好 的热稳定性, 在聚集状态下具有高的荧光量子产率. 化 合物 10 和 11 在 $\mathrm{H}_{2} \mathrm{O}$ (不良溶剂)的体积含量为 $90 \%$ 的
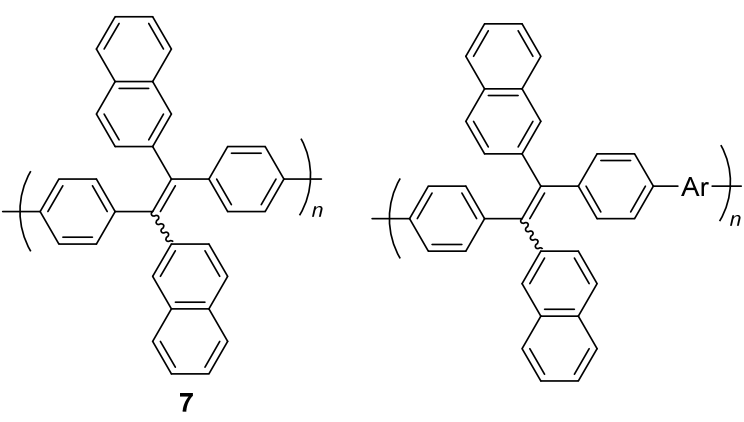

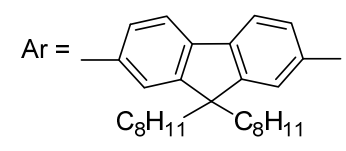

8

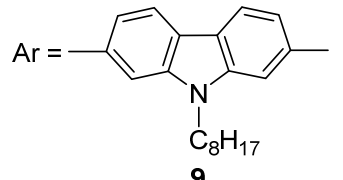

9
$\mathrm{H}_{2} \mathrm{O}-\mathrm{THF}$ 溶液中, 由于 AIE 效应而发出强烈的苂光, 而 当加入了 TNP 时, 发生了明显的荧光猝灭, 其猝灭常数 分别可高达 560000 和 $376000 \mathrm{~L} / \mathrm{mol}$. 其苂光猝灭机理 是: 树枝状的 10 和 11 具有的三维拓扑结构使其比有机 小分子或线性聚合物含有更多的分子孔穴，通过电荷转 移络合而捕获了 TNP 分子 ${ }^{[40,41]}$, 从而发生解聚集，导致 苂光猝灭. 这表明 TPE 衍生物 10 和 11 可应用于 TNP 的检测, 为检测爆炸物的苂光分子设计提供了新的思 路.

Zheng 等 ${ }^{[42,43]}$ 最近报道了系列具有 AIE 效应的可检 测特定爆炸物的大环化合物, 例如 TPE 席夫碱大环化合 物 12, 在水中能聚集诱导发出很强的黄色荧光. 在多种 含硝基芳香化合物存在时, 化合物 12 可以选择性地与 TNP 和 2,4-二硝基苯酚(DNP)作用，导致其荧光强度降 低. 在只加入 $1 \mathrm{nmol} / \mathrm{L}(0.2 \mu \mathrm{g} / \mathrm{L})$ 的 DNP 或 $5 \mathrm{nmol} / \mathrm{L}(1.1$ $\mu \mathrm{g} / \mathrm{L})$ 的 TNP 的情况下, 化合物 12 的荧光强度都能迅速 下降, 显示出极高的灵敏度. 此外, 实验结果还显示出 化合物 12 与 DNP 作用具有荧光完全猝灭现象, 而与 TNP 作用则只是荧光强度降低但不至于猝灭, 这提供了 一个区分 DNP 和 TNP 的新途径. 此外, 该课题组 ${ }^{[43]}$ 还 成功合成了能够灵敏地对 2,4,6-三硝基甲苯(TNT)进行 检测的 TPE 衍生物 13, 在含 $\mathrm{H}_{2} \mathrm{O}$ 体积分数为 $95 \%$ 的 $\mathrm{H}_{2} \mathrm{O}-\mathrm{THF}$ 混合悬浮液中, 相对于其它硝基芳香化合物, TNT 对 13 表现出更明显的苂光淬灭效果. 他们的研究 成果为特定爆炸物的检测开拓了新的方向. 

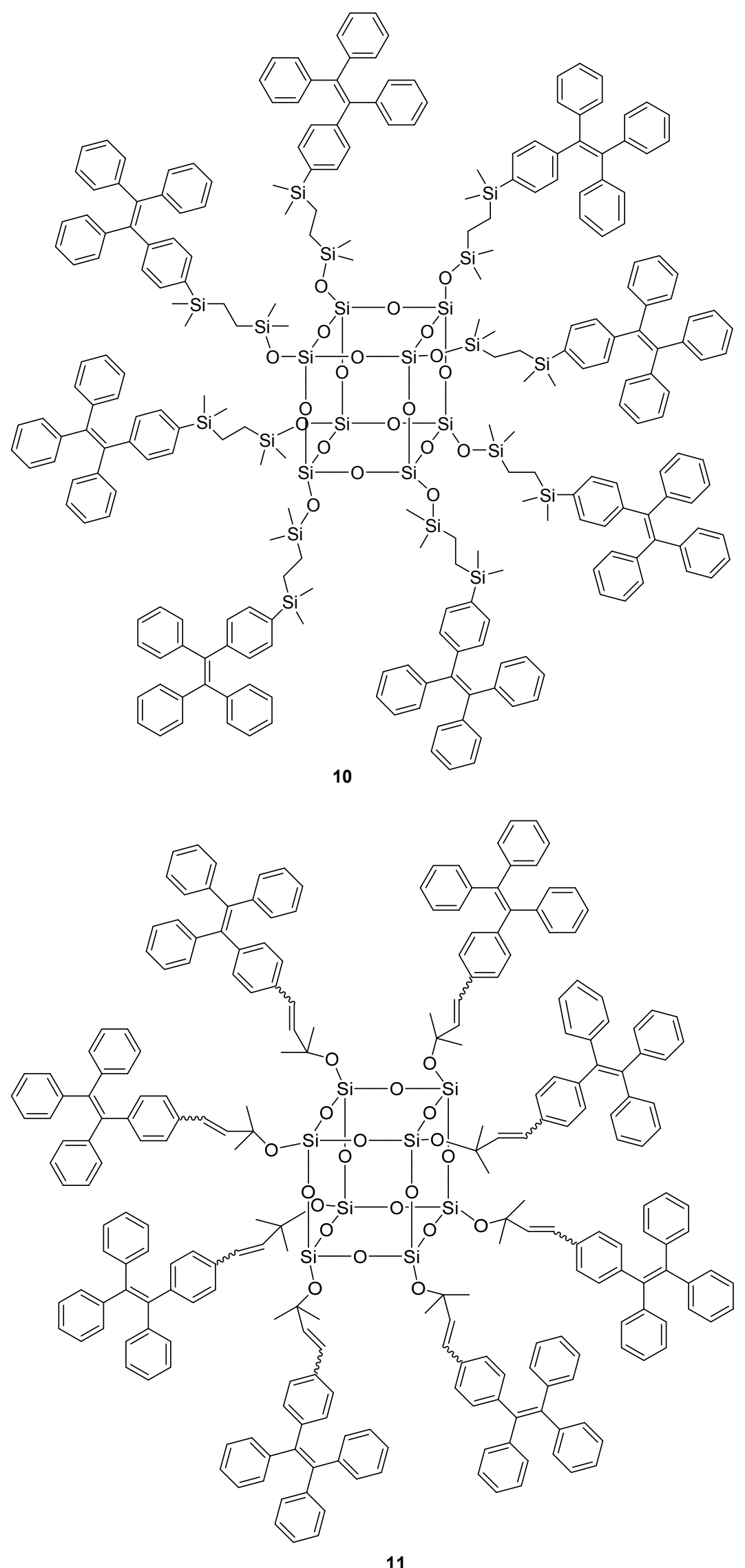

11 

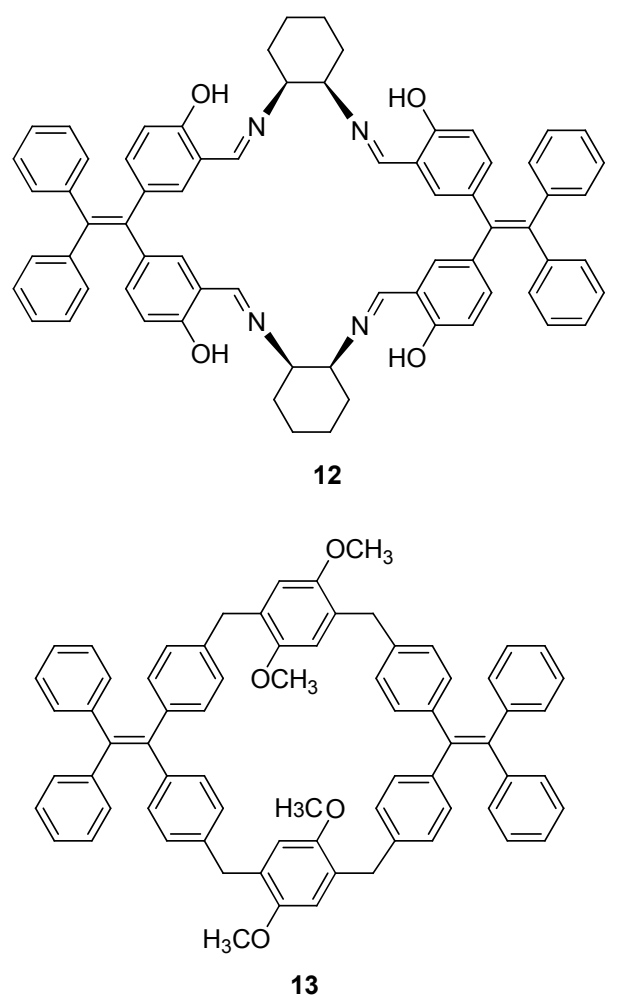

\section{$1.3 \mathrm{pH}$ 值的测定}

2015 年, $\mathrm{Ye}$ 等 ${ }^{[44]}$ 合成了一种能检测 $\mathrm{pH}$ 的 TPE 苂光 探针 14, 其在 $\mathrm{H}_{2} \mathrm{O}-\mathrm{THF}(V: V=2: 8)$ 溶液中, $\mathrm{pH}$ 检测 范围为 $1.99 \sim 11.64 .14$ 在酸性溶液中 $(\mathrm{pH}$ 范围为 $1.99 \sim$ 7.02)只能在 $377 \mathrm{~nm}$ 处观察到发射单体的苂光猝灭. 而 处于碱性条件时, 由于 AIE 效应, 将在 $483 \mathrm{~nm}$ 处出现新 的荧光带. 在 $\mathrm{pH}$ 值由 7.02 增加到 8.50 的过程中, 其荧 光强度按一定比例在发射波长为 377 和 $483 \mathrm{~nm}$ 处分别 递减和递增. 随着 $\mathrm{pH}$ 值从 8.50 不断增加到 11.64 , 在 $483 \mathrm{~nm}$ 处能够观察到明显的荧光带. 该苂光探针的报 导提供了一种利用 AIE 效应检测 $\mathrm{pH}$ 值的新方法.

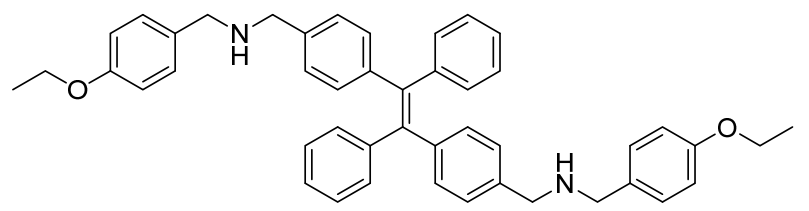

14
Liang 等 ${ }^{[45]}$ 报道了一种由含肽的 TPE 衍生物 15 构 成的具有可逆响应的新型 $\mathrm{pH}$ 荧光水凝胶, 这种智能发 光系统对 $\mathrm{pH}$ 传感器具有潜在的应用价值. 更重要的是, 通过改变末端残留肽序列, 如将赖氨酸改变为组氨酸, 再改变为谷氨酸, 有望得到 $\mathrm{pH}$ 响应值不同的一系列共 轭 TPE 肽衍生物, 因此, 可以制作用于检测一定 $\mathrm{pH}$ 值 范围的纳米探针. 这些研究成果为针对于 $\mathrm{pH}$ 的智能荧 光探测系统的设计提供了一种新思路.

Chen 等 ${ }^{[46]}$ 合成了一种能检测 $\mathrm{pH}$ 值的 TPE 衍生物 16 , 其具有荧光响应的 $\mathrm{pH}$ 范围为 $0 \sim 14$. 该化合物的 $\mathrm{pH}$ 响应机理如 Scheme 1 所示, 由对应文献数据分析 ${ }^{[47]}$ 可知, 以 TPE 为基元且含有一个 $N$-烷基吲哚的化合物 16 具有 AIE 效应和强的斯托克斯位移( $>185 \mathrm{~nm}$ ). 由于 16 的 AIE 效应和对 $\mathrm{OH}^{-} / \mathrm{H}^{+}$的反应性能, 可显示不同色 度的苂光响应，使其具有很宽的 $\mathrm{pH}$ 值感测范围，并呈 现出 “开-关十调节器” 的效果: 在 $\mathrm{pH}<5$ 时发强烈的 红色荧光 $\left(\lambda_{\mathrm{em}}=630 \mathrm{~nm}\right)$, 在 $\mathrm{pH}=5 \sim 7$ 时, 发中度红苂 光, 在 $\mathrm{pH}=7 \sim 10$ 范围内, 几乎没有荧光, 而当 $\mathrm{pH}=$ $10 \sim 14$, 显示弱的蓝色荧光, 在碱性更强的情况下, 蓝 色荧光增强 $\left(\lambda_{\mathrm{em}}=480 \mathrm{~nm}\right)$. 在整个过程中, 化合物 16 与 $\mathrm{OH}^{-} / \mathrm{H}^{+}$的化学反应先起 “开-关” 的作用, 而其 AIE 效 应充当 “调节器” . 同时, 随着 $\mathrm{pH}$ 值由 1 上升到 13 , 在 $440 \mathrm{~nm}$ 处的吸收峰减少直至消失, 而在 $330 \mathrm{~nm}$ 处的新 峰增加, 从而导致溶液颜色从黄色变为无色. 值得注意 的是，该化合物在 $5 \sim 7$ 的生理 $\mathrm{pH}$ 范围内, 苂光强度与 $\mathrm{pH}$ 值具有良好的线性关系，表明该化合物在于对生物 体内 $\mathrm{pH}$ 值的探测方面具有潜在的应用价值.

\section{$1.4 \mathrm{CO}_{2}$ 气体检测}

Wong 等 ${ }^{[48]}$ 于 2015 年开发出一种能检测 $\mathrm{CO}_{2}$ 的水 溶性 TPE 衍生物 17 , 当在含有 17 的水溶液中通入 $\mathrm{CO}_{2}$ 气体时, 可观察到显著的颜色变化和荧光增强. 在水溶 液中, 化合物 17 对 $\mathrm{CO}_{2}$ 的检测非常灵敏, 其检测限可低 达 $2.4 \times 10^{-6} \mathrm{~mol} / \mathrm{L}$. 为了探索化合物 17 对 $\mathrm{CO}_{2}$ 检测的 实际应用, 该课题组将化合物 17 与羊甲基纤维素钠混 合于水溶液中, 成功研制出一种可有效地检测 $\mathrm{CO}_{2}$ 气体 的多孔膜. 更重要的是, 该化合物对活细胞还表现出低 毒性，可用于检测活细胞外部 $\mathrm{CO}_{2}$ 的浓度变化.

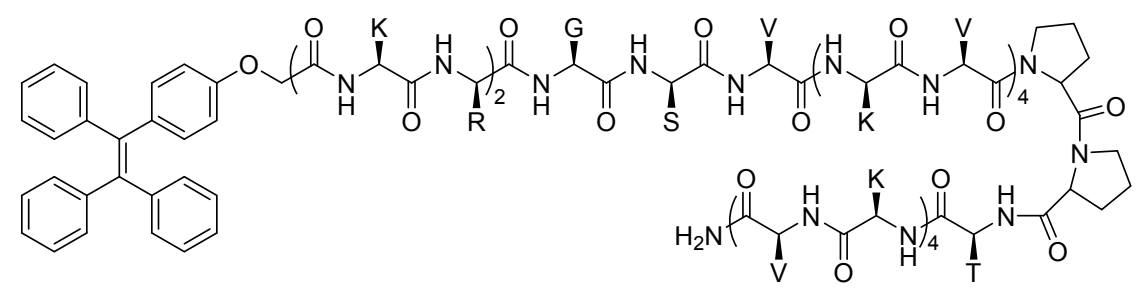

15 


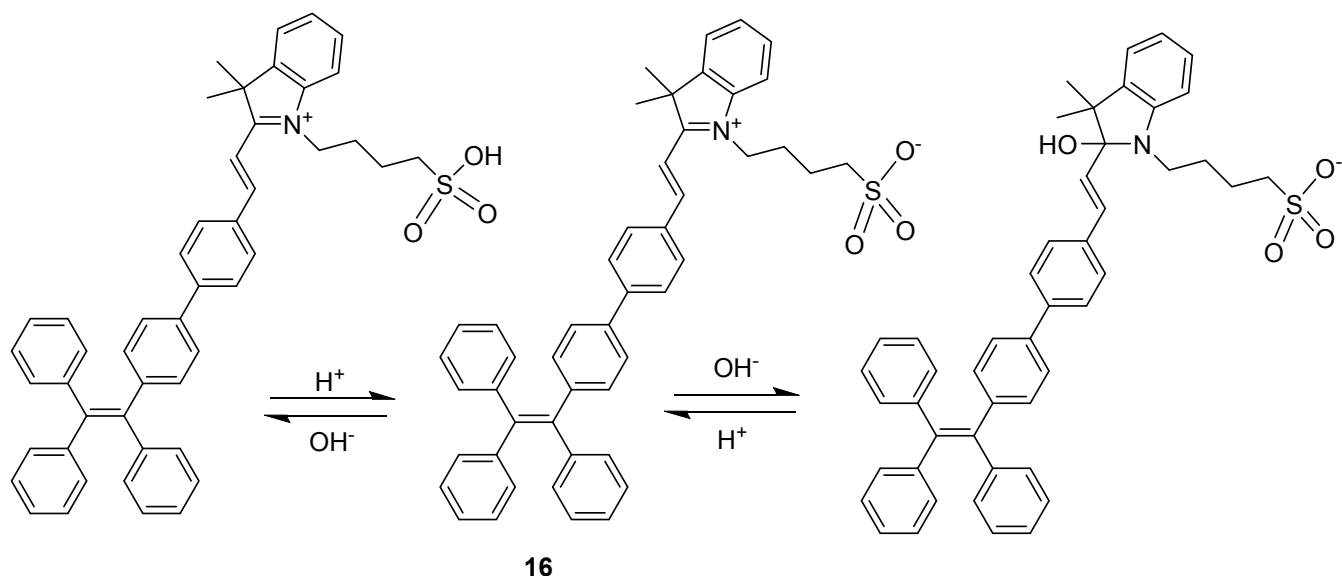

图式 1 化合物 16 的 $\mathrm{pH}$ 响应机理

Scheme 1 Sensing mechanism of compound $\mathbf{1 6}$ for the detection of $\mathrm{pH}$

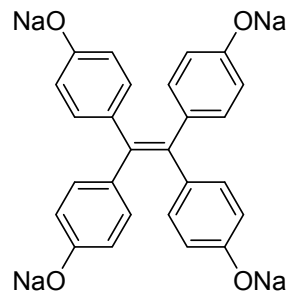

17

Mainak 等 ${ }^{[99]}$ 开发了一种能灵敏检测水溶液中溶解 的二氧化碳(dissolved carbon dioxide, $\mathrm{dCO}_{2}$ ) 的方法: 设 计合成了一种具有 AIE 效应的 TPE 衍生物 18, 结合一 种具有胺官能团的壳聚糖聚合物, 通过离子诱导法使其 自主聚集而发荧光. 检测机理为: 在 $\mathrm{dCO}_{2}$ 存在的情况 下, 电中性的壳聚糖由于胺基质子化而转化为带正电的 物质, 与带负电荷的 18 通过静电作用而聚集, 从而发出 很强的蓝色荧光, $\mathrm{dCO}_{2}$ 的浓度越高, 壳聚糖聚合物所能 得到的电荷密度就越大. 相应地, TPE 衍生物 18 的聚集 程度就会越大, 发出的苂光也更明显. 该方法的灵敏度 很好, 检测限可达 $5 \times 10^{-6} \mathrm{~mol} / \mathrm{L}$.

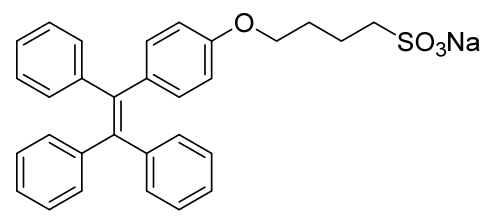

18

Zhang 等 ${ }^{[50]}$ 将聚乙烯亚胺(PEI)与 TPE 连接构建了 一种能简便、快速地检测 $\mathrm{CO}_{2}$ 气体的苂光化学传感器 19. 其检测原理是利用 PEI 上的烷基胺与 $\mathrm{CO}_{2}$ 的反应来 诱导 19 实现 “溶液到沉淀” 的相变, 从而发生聚集诱导 发光. 它可在乙醇这一相对环保的介质中工作, 避免了 具有难闻气味的有毒胺类化合物的使用. 该系统对于
水、一氧化碳、二氧化硫、硫化氢气体以及许多常见的 挥发性有机化合物具有很强的共存能力. 上述特性使得 这类苂光化学传感器具有巨大的应用潜力.<smiles>CC(C)CN(CCN)CCNCCN1CCNCCN(CCNCCOc2ccc(C(=C(c3ccccc3)c3ccccc3)c3ccccc3)cc2)CCN(CCNCCN)CCN(CCN)CC1</smiles>

19

\section{5 其它检测}

Tang 等 ${ }^{[51]}$ 将 TPE 衍生物单体、 $N$-异丙基甲基甲酰 胺 (NIPAM) 单体以及甲基丙烯酸寡聚乙二醇酯 (OEGMA)单体(或甲基丙烯酸甲酯(MMA)单体)通过自 由基聚合反应，得到了一系列温度响应型聚合物，即 20 (Eq. 1)和 21 (Eq. 2). 通过改变单体 NIPAM 和 OEGMA (或 MMA)的配比来微调其聚合物的亲水性，从而达到 调节这些温度响应聚合物的最低临界共溶温度(LCST) 和温度测量范围的效果，当温度低于其 LCST 时，聚合 物链与水分子之间形成了氢键，导致这些聚合物因溶解 度增加而发生苂光减弱, 而当温度高于其 LCST 时, 有 利于链内氢键代替了聚合物链与水分子之间形成的氢 键而聚集, 发生苂光增强. 这些温度响应聚合物的设计 为温度的检测提供了一种新方法.

Tang 等 ${ }^{[2]}$ 还设计合成了能够有效测量液体粘度的 三种 TPE 衍生物探针 22, 23 和 $\mathbf{2 4}$, 在乙二醇-甘油混合 液体中，随着甘油含量的增加，其苂光强度都逐渐增大， 这是由于介质的粘度越大, 其空隙率就越小, 溶剂与这 些 TPE 衍生物分子的摩擦力越大，粘度大的介质使得这 些 AIE 分子的分子内旋转受限, 阻碍了其非辐射衰减, 导致荧光增强. 22, 23 和 24 测量粘性溶液的粘度时，灵 

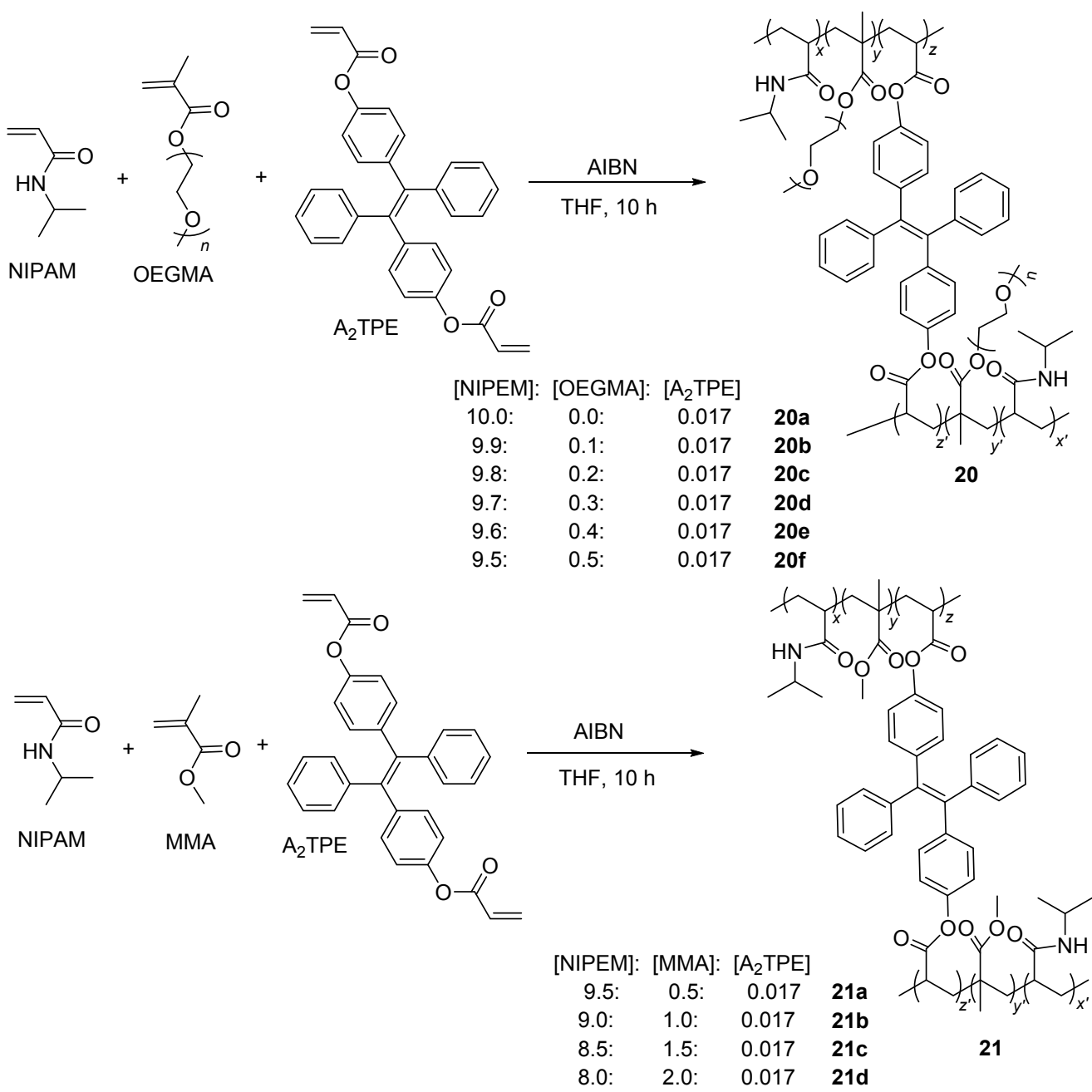

敏度依次增高，其所能测的粘度系数分别可高达 $46 \%$, 93\%和 $98 \%$.

\section{2 生物探针}

\section{1 生物分子传感}

Tang 等 ${ }^{[53]}$ 将具有 AIE 效应的含 TPE 的功能基缀合 到特定的单链核苷酸, 制作了对特定 DNA 有识别作用 的苂光探针 25 和 26. 该探针在水溶液中呈弱苂光, 但 与其对应的互补链杂交作用后苂光大大增强, 能够区分 一个碱基对突变的序列并表现出良好的选择性, 能检测 具有相应特异性序列的 DNA. 若将两个探针彼此杂交 可限制 AIE 基团的自由旋转, 从而进一步增强其苂光信 号的输出.

Tang 等 ${ }^{[54]}$ 通过赖氨酸将亲水性的天门冬氨酸-谷氨 酸基团和一个疏水 AIE 苂光基团进行偶联，成功合成了 具有 AIE 效应并对半胱天冬酶具有特异性识别的探针 27. 该探针具有良好的水溶性, 在水溶液中几乎不发苂 光, 但能够与半胱天冬酶-3 或半胱天冬酶-7 发生作用: 这些蛋白酶在细胞凋亡过程能够切割探针 27 外围的氨
基酸片段，释放出疏水性的 AIE 苂光基团中心，进而发 生聚集使得其苂光增强. 该探针的特殊之处还在于：无 论是在溶液还是活细胞中, 对半胱天冬酶-3/-7 的活动 都具有高信噪比的实时监控. 这可为䇥选酶抑制剂和评 估细胞调亡相关的药物提供很好的检测方法.

2 型糖尿病 (T2DM) 是一种常见的代谢疾病，在全世 界的发病率不断增加. 近年来, 基于肠促胰岛激素独特 生理机制而研发的创新口服降糖药物二肽基肽酶 4 抑制 剂(DPP-4 抑制剂), 因其强效降糖、保护胰岛功能、可 延缓疾病进程、安全性良好等治疗优势而备受关 注 ${ }^{[55 ~ 57]}$. 于是, 通过检测生物样品中 DPP-4 含量来判断 DPP-4 抑制剂的作用成效对于 2 型糖尿病的治疗尤为重 要. 基于此, Cheng 等 ${ }^{[58]}$ 于 2016 年首次报道了具有 AIE 效应且具有优异的苂光切换特性的 DPP-4 苂光探针 28 . 他们以 TPE 为基元，通过连接引入特异性肽，使得该探 针在生物体内和体外都能以一定的线性范围灵敏地检 测 DPP-4. 探针 28 已成功地应用在活细胞和斑马鱼中笁 选 DPP-4 抑制剂. 这提供了一种发现抗糖尿病药物的新 方法, 对治疗 2 型糖尿病具有重要意义. 


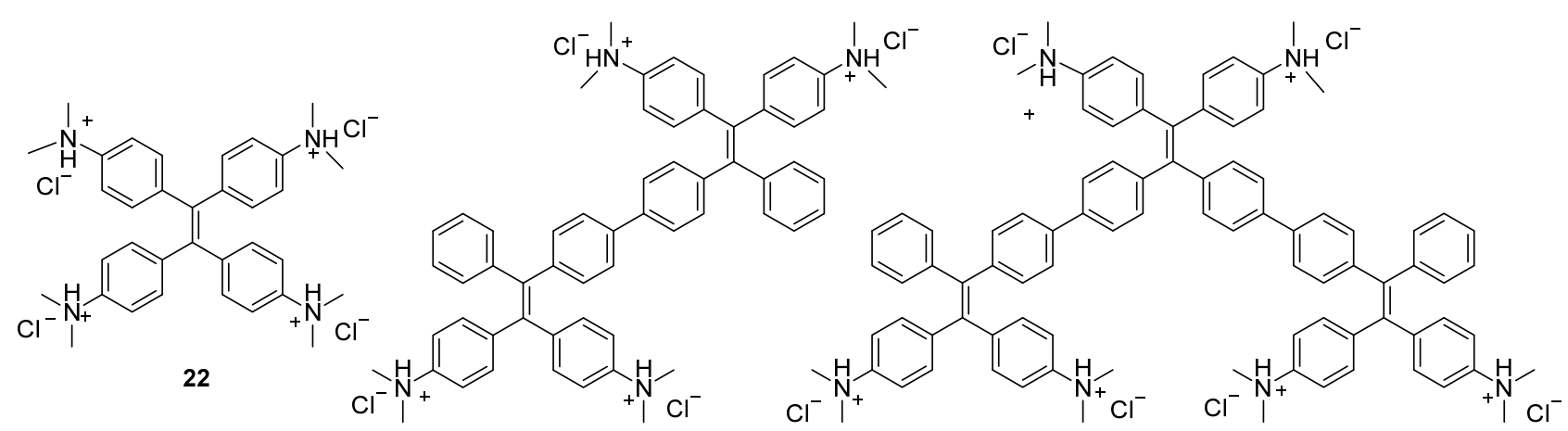

23

24

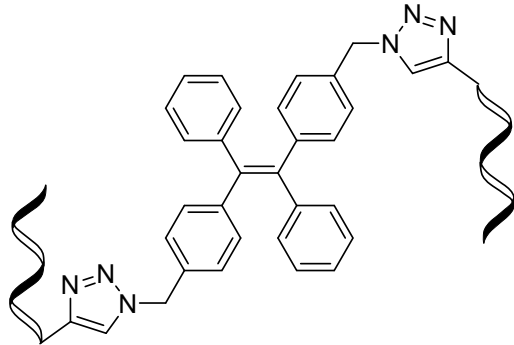

25

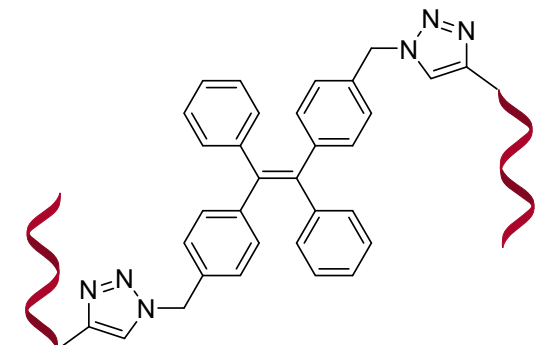

26

oligonucleotide DNA1:5'-AGC ACC CAC ATA GTC AAG AT-3'

oligonucleotide DNA2:5'-ATC TTG ACT ATG TGG GTG CT-3'

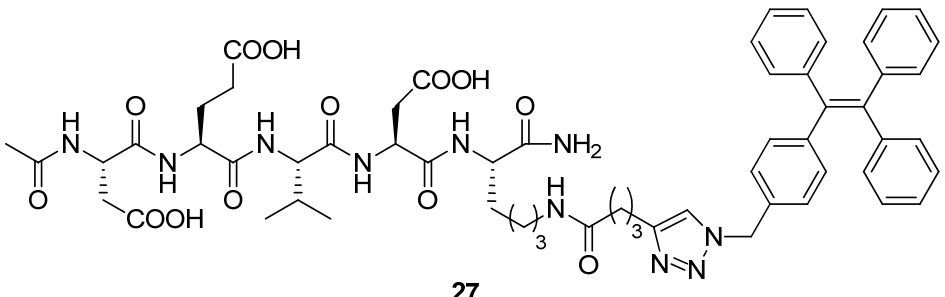<smiles>N[C@@H](CCC(=O)O)C(=O)N1CCC[C@H]1C(=O)N[C@@H](Cc1ccccc1)C(=O)N[C@@H](CCCCNC(=O)COc1ccc(C(=C(c2ccccc2)c2ccccc2)c2ccccc2)cc1)C(=O)O</smiles>

28

硫醇是生物体中许多蛋白质和小分子的重要组成 部分, 在细胞的抗氧化系统中发挥着重要作用 ${ }^{[59]}$, 定量 检测硫醇在生物化学和临床化学中具有重要的意义.

2014 年, Tang 等 ${ }^{[60]}$ 设计合成了一个含席夫碱形式的 TPE-香豆素混合苂光基团化合物 29. 化合物 29 可与硫 醇作用并表现出丰富的光学性能和化学反应, 因此可应 用于检测硫醇的导通探头. 该课题组通过核磁和紫外吸 收光谱的分析说明了这种染料可作为生物硫醇的苂光 探针的合理性.

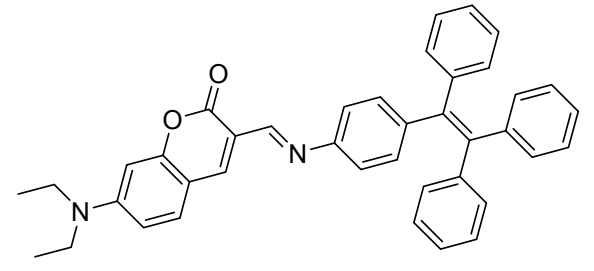

29

Tang 等 ${ }^{[61]}$ 还设计合成了针对于整合蛋白 $\alpha_{v} \beta_{3}$ 的目 标苂光探针 30 , 应用于细胞内的特定硫醇成像. 该探针 
由具有五个天冬氨酸的高水溶性目标环肽(cRGD)、一个 TPE 苂光团和一个硫醇特异性裂解的二硫化物连接而 成. 30 能与整合蛋白 $\alpha_{\nu} \beta_{3}$ 高度结合成为独特的分子生物 标记, 对及早发现和治疗快速增长的实体肿瘤具有重要 意义. 该探针具有高水溶性且在水溶剂中几乎不发光, 而二硫化物接头与硫醇作用发生裂解后将导致苂光信 号增强. 该探针可应用于肿瘤细胞硫醇含量的实时监 测.

过氧化氢 $\left(\mathrm{H}_{2} \mathrm{O}_{2}\right)$ 作为一种活性氧, 在生物体的氧化 应激和信号传导中发挥着至关重要的作用 ${ }^{[62,63]}$. 为了能 灵敏检测生物体内的 $\mathrm{H}_{2} \mathrm{O}_{2}$ 含量, 2015 年, $\mathrm{Li}$ 等 ${ }^{[64]}$ 设计合 成了一种能够在活细胞中快速检测 $\mathrm{H}_{2} \mathrm{O}_{2}$ 的 TPE 衍生物 31, 其检测机理是: 引入的 $\mathrm{H}_{2} \mathrm{O}_{2}$ 使得硼酸频哪醇酯部 位转化为酚差基, 从而聚集而发生苂光增强, 实现了对 $\mathrm{H}_{2} \mathrm{O}_{2}$ 进行快速的定量检测, 其检测限低至 $0.52 \mu \mathrm{mol} / \mathrm{L}$ (Eq. 3).

\section{2 生物成像}

生物成像是一种重要的医学方法, 可以提供各种生 理和病理过程中的关键信息, 例如癌症的检测和治疗、 干细胞移植、致免疫性等. 在过去的几十年里, 不同的 生物成像模态, 例如单光子发射计算机断层摄影、磁共 振成像和苂光成像等都获得了快速发展 ${ }^{[65 ~ 74]}$. 其中, 利 用苂光作为输出信号的生物成像因为信号强度好、生物 相容性高和可设计苂光纳米探针等优点而吸引了许多 科学家的研究兴趣. TPE 类衍生物的 AIE 染料最近已被 广泛应用于生物成像.

2016 年, $\mathrm{Li}$ 等 ${ }^{[75]}$ 报道了一种具有 AIE 效应的两亲分
子 32, 它是由 TPE 疏水部分连接亲水性季铵盐来构成. 该化合物在不同浓度下可以自主聚集形成直径范围为 $55 \sim 385 \mathrm{~nm}$ 的纳米聚集体. 不同浓度的水溶液苂光光 谱检测表明, 32 具有良好的水分散性、极低的临界胶团 浓度 $\left(2.0 \times 10^{-6} \mathrm{~mol} / \mathrm{L}\right)$ 、强烈的蓝色荧光以及优异的耐 光漂白性. 此外, 这类化合物的纳米聚集体对细胞膜具 有良好的通透性, 且在生物成像中与 HeLa 细胞具有优 良的生物相容性. 这项工作为具有 AIE 效应的两亲分子 的设计开辟了一种新途径, 在生物成像领域具有很好的 应用潜力.

Tang 等 ${ }^{[76]}$ 设计合成了一种显著的双态荧光核磁共 振成像(MRI)对比剂 33, 可作为阳性血池和肝特异性 MRI 造影剂. 该两性分子在水溶液中能形成具有强烈苂 光的纳米胶束, 即典型的 AIE 效应. 该化合物作为 MRI 造影剂, 可在水中出现与马根维显等商业剂类似的磁弛 豫. 与马根维显(钝喷酸葡胺注射液)相比, 化合物 $\mathbf{3 3}$ 的 纳米聚集体在活大鼠中的循环寿命可从 $10 \mathrm{~min}$ 延长至 1 $h$, 且其对肝脏具有相对高的特异性: MRI 成像时在肝脏 中注射 33, 经过 $150 \mathrm{~min}$ 后还能有很强的苂光信号. 值 得一提的是, 这些纳米颗粒可以在循环过程中分解成小 分子, 通过肾小球滤过逐渐排出体外, 因而有望作为肝 特定 MRI 对比剂应用于临床诊断.

Huang 等 ${ }^{[77]}$ 合成了分别含富电子荎和缺电子百草 枯的 TPE 衍生物 34 和 35 . 通过电荷转移相互作用的驱 动, 34 和 35 以一维填充模式自主聚集成纳米棒, 从而导 致其分子内旋转受限，有效地提高了 AIE 效应. 该类化 合物可用作活细胞成像剂对癌细胞进行染色. 在癌细胞

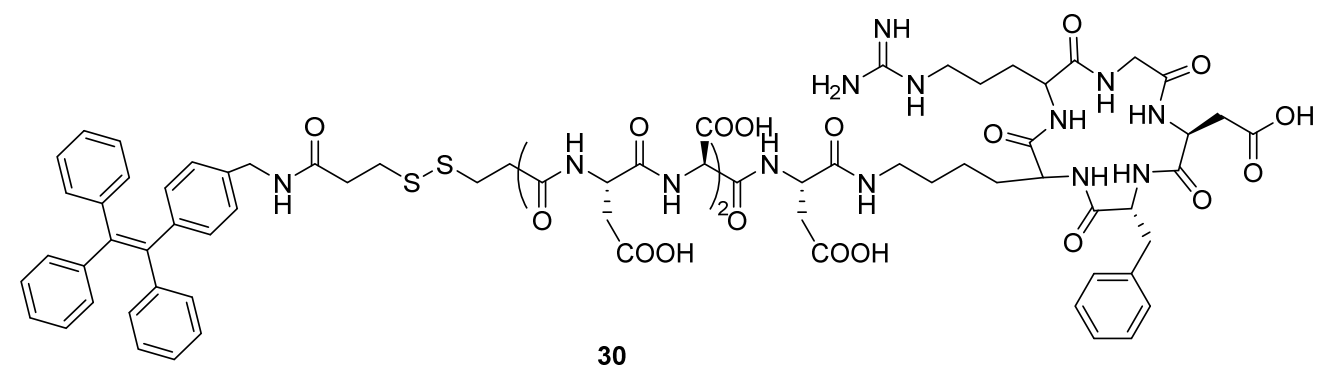<smiles>CC1(C)OB(c2ccc(C(=C(c3ccccc3)c3ccc(B4OC(C)(C)C(C)(C)O4)cc3)c3ccccc3)cc2)OC1(C)C</smiles><smiles>CCN(CC)CCOC(=O)c1ccc(C(=C(c2ccccc2)c2ccccc2)c2ccccc2)cc1</smiles>

32 


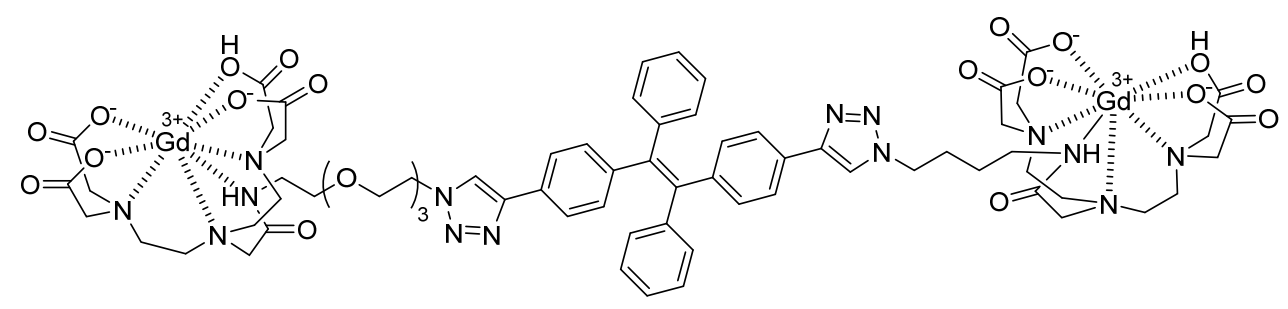

33

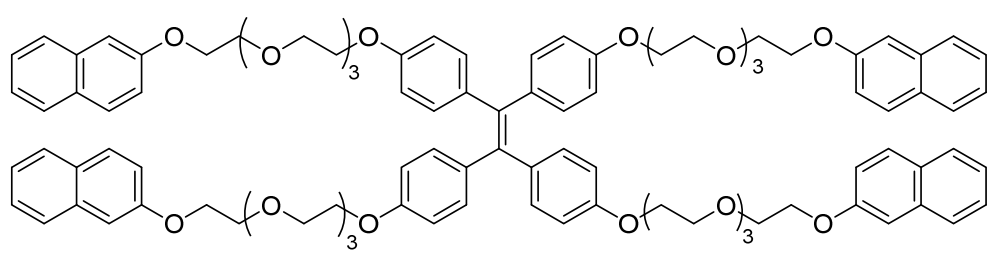

34

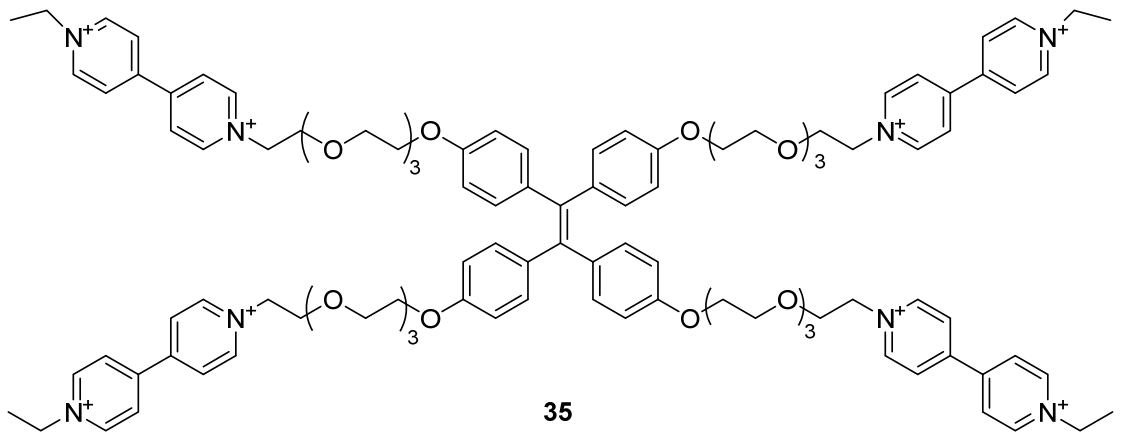

中, 34 和 35 相互作用后形成稳定的电荷转移复合体系, 进而导致 TPE 基芳环分子内旋转受限而诱导其在细胞 质中的 AIE 现象增强. 这些结果表明, AIE 效应与超分 子化学的组合在生物学和药学等相关领域中应用潜力 巨大，例如应用于生物传感器、药物和基因递送系统或 细胞成像等.

\section{OLED 发光器件}

Tang 等 ${ }^{[78]}$ 以 TPE 为基本单元, 分别引入二苯基氨 基和二米基硼作为电子供体和电子受体成功合成了两 种 TPE 衍生物 36 和 37 , 并系统地研究了两者的热稳定 性、光物理性质、溶剂化、荧光衰变、电子结构、电化 学行为及电致发光特性, 讨论了分子内电荷转移跃迁 (intramolecular charge transfer, ICT)对其光电性能的影 响. 37 表现出很强的 ICT 作用并伴随其特征吸收峰，而 36 则表现出弱的 ICT 作用, 吸收带明显蓝移. 这两种 TPE 衍生物在固体薄膜状态下都因 AIE 效应而发出强 烈的苂光, 其中, 37 呈绿光, 其固态荧光量子产率 $\phi_{\mathrm{F}}$ 达 到 $64 \%$, 而 36 的呈蓝绿光, 其固态苂光量子产率 $\phi_{\mathrm{F}}$ 高 达 94\%. 相对于 37, 36 显示出更好的光致发光和电致发 光性能: 把 36 作为发光层和空穴运输层制作未经优化 的双层有机发光二极管(OLED), 可获得 5.35\%的外部量 子效率. 这种简单却能得到优异光致发光效率的器件, 对减少相关设备的制造成本具有重要意义, 并提供了一 种可用于制作非掺杂 OLED 器件的合理方案.

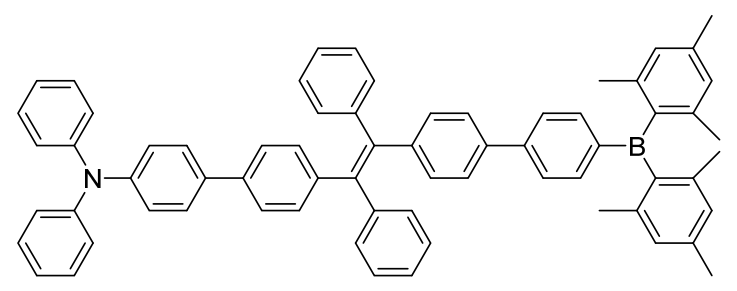

36

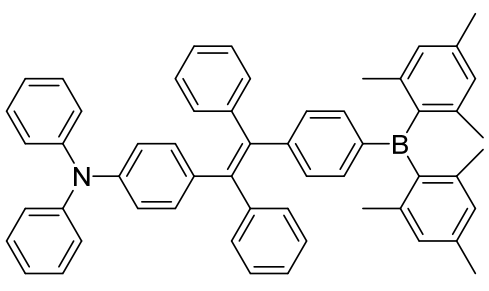

37 
$\mathrm{Li}$ 等 ${ }^{[79]}$ 通过连接噻咯和 TPE 设计合成了两种具有 AIE 效应的 TPE 衍生物 38 和 39. 研究表明, 这两种化 合物都具有良好的热稳定性和优异的电致发光性能, 由 37 制作的 OLED 器件发天蓝色光, 其电致发光波长为 $488 \mathrm{~nm}$, 最大亮度达到 $27161 \mathrm{~cd} \cdot \mathrm{m}^{-2}$, 发光效率为 8.04 $\mathrm{cd} / \mathrm{A}$, 流明效率为 $6.17 \mathrm{~lm} / \mathrm{W}$, 外量子效率可达 3.38\%; 而由 38 制作的 OLED 器件发深蓝色光, 其电致发光波 长为 $432 \mathrm{~nm}$, 最大亮度达到 $4411 \mathrm{~cd} \cdot \mathrm{m}^{-2}$, 发光效率为 $1.39 \mathrm{~cd} / \mathrm{A}$, 流明效率为 $1.18 \mathrm{~lm} / \mathrm{W}$, 外量子效率可达 $1.21 \%$. 所以, 化合物 $\mathbf{3 8}$ 和 $\mathbf{3 9}$ 可应用于制作非掺杂高效 蓝色 OLED 器件.

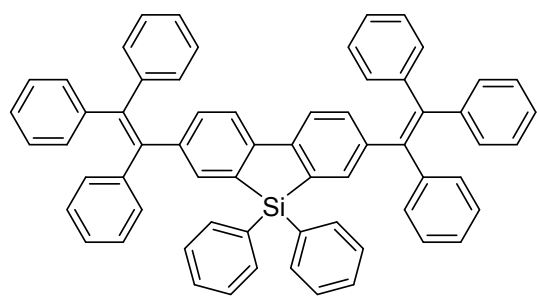

38

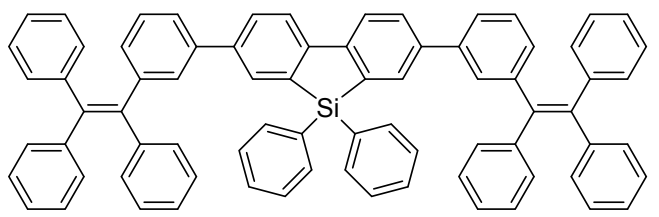

39

2016 年, Xin 等 ${ }^{[80]}$ 以四苯基乙烯-咔唑为基本骨架, 通过芳硼基对/间位取代设计合成了四种具有 AIE 性质 的 TPE 衍生物 40 43, 并针对这些化合物的供体-受体 相互作用与共轭程度对其光致发光和电致发光特性的 影响进行了研究. 实验结果表明, 这些化合物均具有良 好的热稳定性、电化学稳定性和 AIE 特性, 其固态荧光 量子效率 $\phi_{\mathrm{F}}$ 分别可达到 $99.3 \%$ 、48.6\%、34.6\%和 $65.2 \%$. 当使用对位取代的化合物 40 作为发光层构造非掺杂 OLED 器件时, 在导通电压为 $4.8 \mathrm{~V}$ 下可发出绿色荧光, 最大苂光亮度值为 $30210 \mathrm{~cd} \cdot \mathrm{m}^{-2}$ 、最大电流效率可达 $9.96 \mathrm{~cd} / \mathrm{A}$. 使用间位连接的化合物 $\mathbf{4 3}$ 作为发光层构造 的 OLED 器件则发出蓝色荧光, 且有 $16410 \mathrm{~cd} \cdot \mathrm{m}^{-2}$ 的最 大荧光亮度值和 $4.49 \mathrm{~cd} / \mathrm{A}$ 的最大电流效率. 而将 41 和 42 作为发光层构造的 OLED 器件均发出蓝色荧光. 这些 TPE 类化合物的电致发光性质揭示了其在 OLED 发光 器件领域的应用前景.

Tang 等 ${ }^{[81]}$ 成功合成了可用于构造高效非掺杂 OLEDs 且可溶液加工的双极性小分子发光材料, 即热 稳定性良好的 TPE 衍生物 $\mathbf{4 4 \sim 4 6}$. 这些化合物在溶液

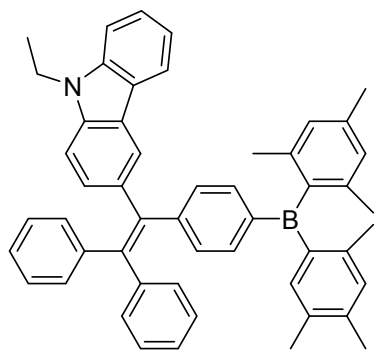

40
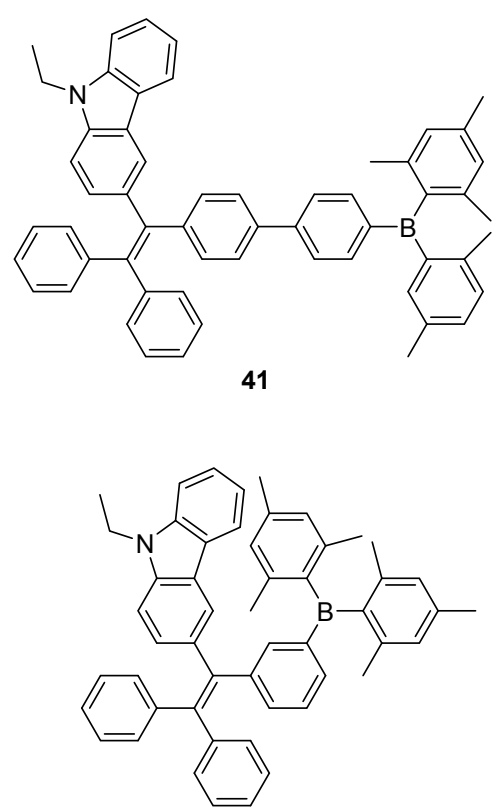

42

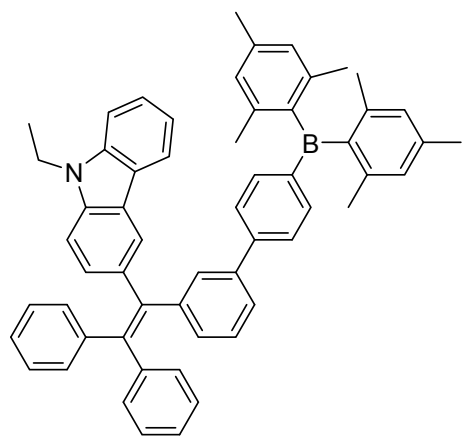

43

中显示弱苂光, 但在固体状态下苂光大大增强, 呈现出 明显的 AIE 效应. $44 \sim 46$ 在固体薄膜中的光致发光波长 分别为 $540 、 528$ 和 $524 \mathrm{~nm}$, 固态苂光量子效率分别高 达 95\%、92\%和 91\%. 由于其良好的成膜能力，它们已 被用作高效非掺杂 OLEDs 的发光材料, 电致发光效率 高达 $8.3 \mathrm{~cd} / \mathrm{A}$. 参阅文献[82 85]可知, $\mathbf{4 4}$ 和 $\mathbf{4 5}$ 均为具 有优异发光性能的可溶液加工的苂光小分子，可被用于 通过溶液加工制备高效 OLEDs. 


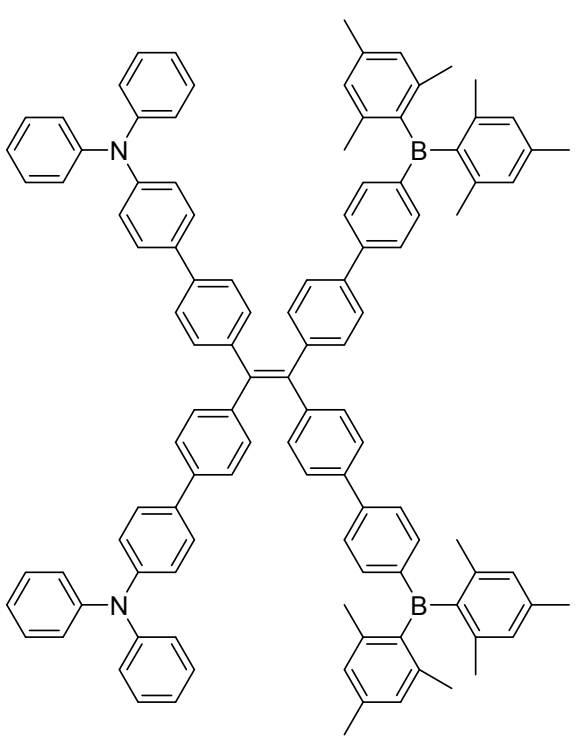

44

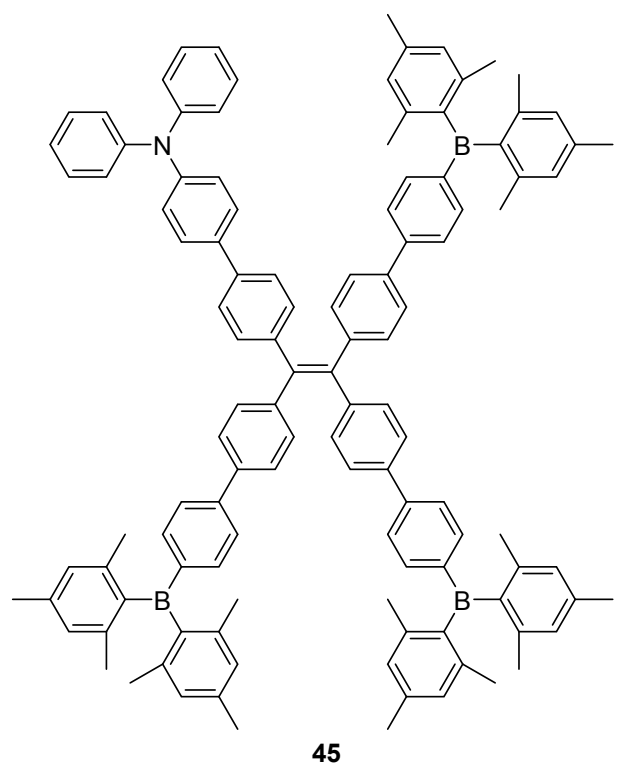

$\mathrm{Li}$ 等 ${ }^{[86}$ 将三苯胺(TPA)和四苯基乙烯(TPE)通过链 接不同部位合成了四种 TPE 衍生物 47 50, 并对其热、 光、电学性能分别进行了充分的研究. 以 TPE 为核心引 入三苯胺结构, 使得其 $\pi-\pi$ 共轭长度得到有效限制而发 射蓝光. 基于这四种材料制作的非掺杂 OLED 可发射出 443 466 nm 的蓝色苂光, 并具有良好的电致发光效率, 其最大亮度、发光效率和流明效率分别可高达 8160 $\mathrm{cd} \cdot \mathrm{m}^{-2} 、 3.79 \mathrm{~cd} / \mathrm{A}$ 和 $2.941 \mathrm{~m} / \mathrm{W}$.

Tang 等 ${ }^{[87]}$ 通过 McMurry 反应设计合成了热稳定性 良好的 TPE 衍生物 $\mathbf{5 1}$ 和 $\mathbf{5 2}$, 它们具有高的固态荧光量 子产率和良好的载流子传输性能, 以 $\mathbf{5 1}$ 和 $\mathbf{5 2}$ 作为发光 层制作的 OLED 器件, 电致发光波长为 488 492 nm 范 围的天蓝色苂光, 其外部量子产率分别可高达 $3.1 \%$ 和

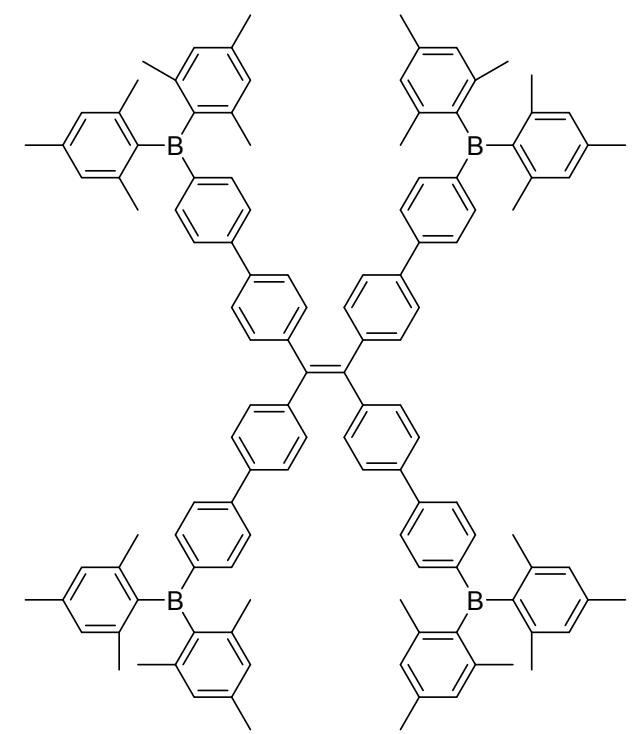

46
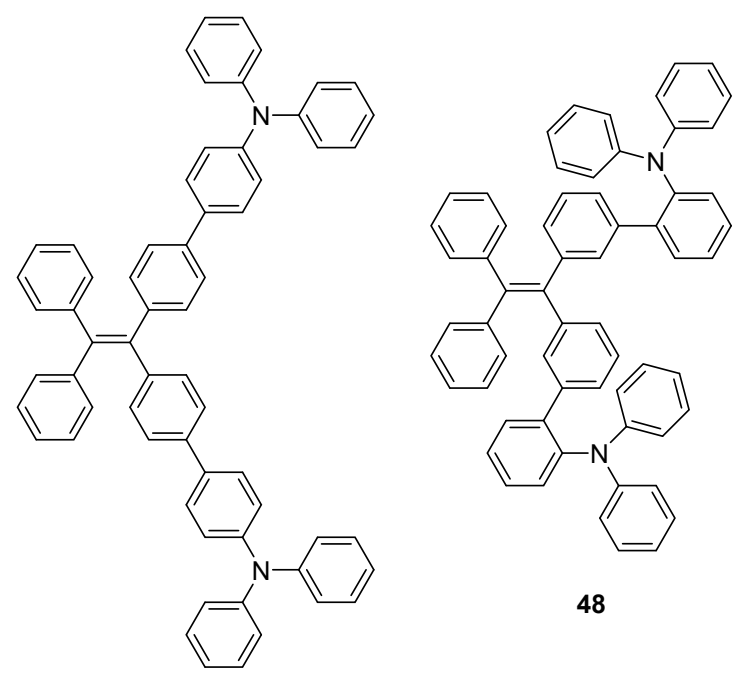

48

$$
47
$$

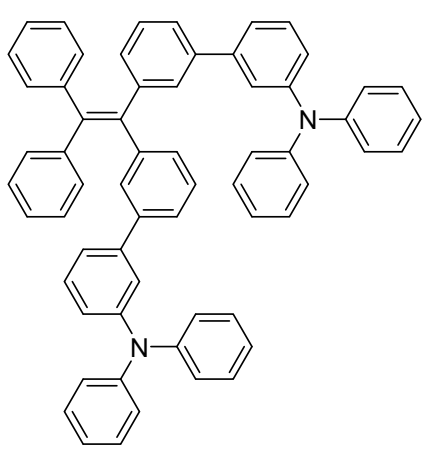

49

$2.4 \%$, 发光效率分别可达 7.9 和 $5.1 \mathrm{~cd} / \mathrm{A}$, 相比 $\mathbf{5 2}$ $\left(3.3 \times 10^{-4}\right.$ 和 $\left.3.7 \times 10^{-4} \mathrm{~cm}^{2} \cdot \mathrm{V}^{-1} \cdot \mathrm{s}^{-1}\right), \mathbf{5 1}$ 具有更高的电 子迁移率和空穴迁移率 $\left(4.9 \times 10^{-4}\right.$ 和 $4.3 \times 10^{-4} \mathrm{~cm}^{2} \cdot \mathrm{V}^{-1}$. $\left.\mathrm{s}^{-1}\right)$, 说明 51 比 52 具有更好的载流子传输能力. 


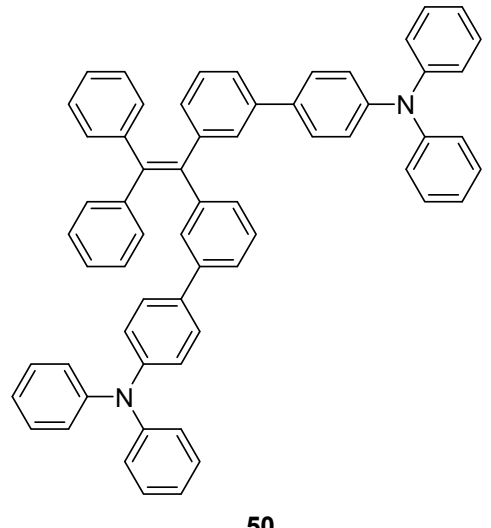

50<smiles>Brc1ccccc1C(=C(c1ccccc1)c1ccccc1)c1ccccc1Br</smiles>

$\operatorname{Ar}=$<smiles>Cc1ccc(-n2c3ccccc3c3ccccc32)cc1</smiles>

51

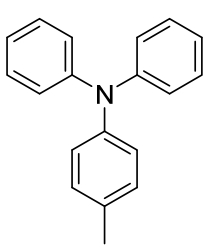

52

\section{4 其他应用}

Ren 等 ${ }^{[88}$ 提出荧光下移(luminescent down-shifting, LDS)应用的新型苂光团的设计策略并成功合成了三种 新的荧光团, 即化合物 53、54 和 55. 这三种 LDS 分子 具有特定的分子内电荷转移和 AIE 特性, 可用于增加 $\mathrm{CdTe}$ 太阳能电池的输出短路电流密度 $\left(\mathrm{J}_{\mathrm{SC}}\right)$. 对上述化 合物的光物理学研究及其在 CdTe 太阳能电池的 PMMA 固体薄膜中的应用研究表明, 这些 LDS 分子具有特定 的光谱性质和 $J_{\mathrm{SC}}$ 增强效应, 其在 $\mathrm{CdTe}$ 太阳能电池的输 出短路电流密度 $J_{\mathrm{SC}}$ 分别高达 $5.69 \%$ 和 $8.88 \%$. 相比传统 的 LDS 分子 Y $083^{[89 \sim 91]}$, 这些荧光团显示出更卓越的 LDS 性能.

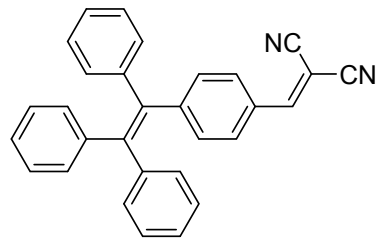

53

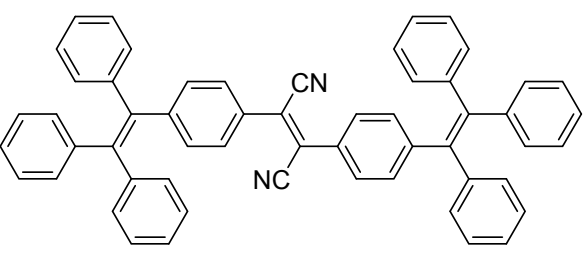

54<smiles>N#CC(C#N)=Cc1ccc(C(=C(c2ccccc2)c2ccccc2)c2ccc(C=C(C#N)C#N)cc2)cc1</smiles>

55

水中或生物体内微生物的快速检测对于食品安全、 环境监测及临床诊断与治疗均具有重要意义. 大肠杆菌 与许多传染病相关联, 能引起各种肠和肠道外感染, 如 腹泻、食物中毒和尿道感染等 ${ }^{[92]}$. 为了定量检测大肠杆 菌, 2015 年, $\mathrm{Li}$ 等 ${ }^{[93]}$ 合成了一种具有 AIE 效应的 TPE 衍 生物 56, 并把它和甘露糖成功连接到聚苯乙烯马来酸 酐共聚物(PSMA)纤维上, 形成了一种可有效定量检测 水溶液中大肠杆菌的检测试纸. 当水溶液中存在大肠杆 菌时，该试纸中接枝在 PSMA 纤维上的甘露糖能与大肠 杆菌菌毛中的 FimH 蛋白进行特异性结合，使得 TPE 衍 生物 56 发生聚集诱导发出强烈荧光. 通过对含不同浓 度的大肠杆菌溶液的测试表明，该试纸有望作为简单、 快速地检测大肠杆菌的一种工具, 其细菌浓度检测限可 低至 $10^{2} \mathrm{CFU} / \mathrm{mL}$.<smiles>Clc1nc(Cl)nc(Oc2ccc(C(=C(c3ccc(Oc4nc(Cl)nc(Cl)n4)cc3)c3ccc(Oc4nc(Cl)nc(Cl)n4)cc3)c3ccc(Oc4nc(Cl)nc(Cl)n4)cc3)cc2)n1</smiles>

Tang 等 ${ }^{[94]}$ 报道了一种能够应用于细菌成像并具有 灭菌性能的 TPE 衍生物 57. 该化合物的水溶性良好，在 水溶液中显示弱荧光, 而细菌的存在会使其激活并发射 苂光，因此它可用于无灭菌过程的细菌成像. 具有两条 长烷基链和带正电荷铵基团的两性 TPE 衍生物 57 可以 插入细菌膜，从而破坏膜的完整性. 在光照条件下，由 于光敏剂诱导活性氧(reactive oxygen species, ROS)的形 成，其杀菌效果大大增强，可有效地杀灭革兰氏阳性和 阴性菌. 实验发现, 含化合物 $\mathbf{5 7}$ 的琼脂平板可以通过施 加光照产生 ROS 而连续有效地对细菌进行杀灭. 这些 实验结果表明，化合物 57 在杀菌材料领域的潜在应用 价值. 


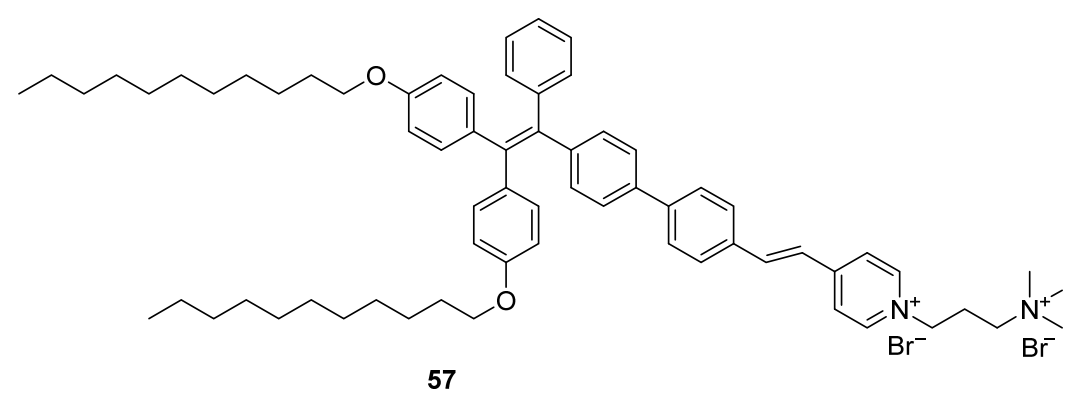

2015 年, Tang 等 ${ }^{[95]}$ 设计合成了具有分子内 $\pi-\pi$ 堆积 作用的 TPE 衍生物 $\mathbf{5 8}$ 和 $\mathbf{5 9}$, 通过扫描电子显微镜基于 断裂-连接技术的实验及其分析计算结果表明: 两个 $\pi$ 堆积的联苯因环内区域表现出明显的空间共轭, 弥补了 较弱的键共轭而成为单分子连接中一个高效的导电通 道. 这类具有空间共轭和键共轭的折叠分子有望广泛应 用于具有多通道电导的新型单分子导线, 对纳米电子器 件的构建和生物氧化还原过程的深入研究具有重要意 义.

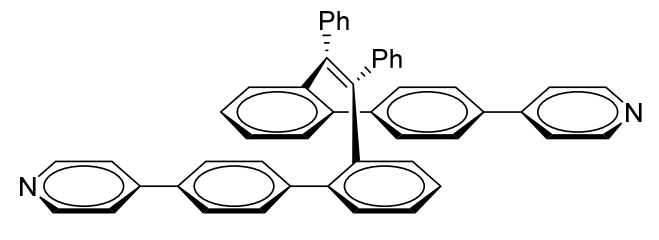

58

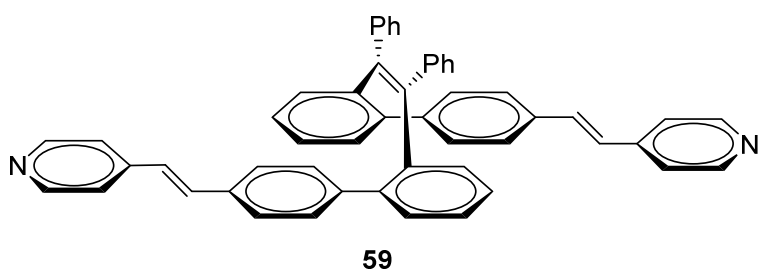

Tang 等 ${ }^{[96]}$ 通过铃木反应设计合成了对称二取代的 双 TPA-TPE 化合物 60, 该化合物在良性溶剂 THF 中, 荧光发射很弱, 但其固体薄膜的荧光强度大大增强. 60 具有高的 HOMO 能级 $(-5.15 \mathrm{eV})$, 实验测得其空穴迁 移率为 $5.2 \times 10^{-4} \mathrm{~cm}^{2} \cdot \mathrm{V}^{-1} \cdot \mathrm{s}^{-1}$, 表明该化合物具有良好 的空穴传输性能. 用 60 的非晶薄膜制作的场效应晶体 管具有高达 $2.6 \times 10^{-3} \mathrm{~cm}^{2} \cdot \mathrm{V}^{-1} \cdot \mathrm{s}^{-1}$ 的载流子迁移率, 其 高效的光致发光和电致发光性能使得 60 在场效应晶体 管等电子光学器件中具有良好的应用前景.

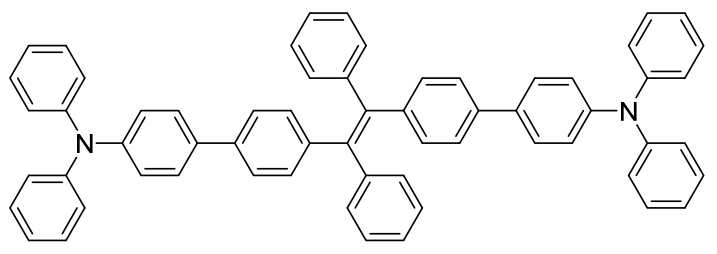

60

\section{5 结束语}

四苯乙烯衍生物具有很强的 AIE 效应，拥有高的苂 光量子产率，且易于官能化、合成方便、容易设计成对 特定离子、蛋白质等物质具有高选择性的苂光探针, 也 可应用于高性能 OLEDs 等光学器件的设计. 大量 TPE 衍生物表现出良好的生物相容性、优良的耐光性和高选 择性，使其在细胞成像、药物释放、细菌检测等医疗、 环保领域具有潜在的应用价值, 而且其在苂光传感、光 电材料、医药等众多领域的应用研究已取得许多重要成 果.

尽管如此, 针对 TPE 衍生物的大部分研究还处于实 验室研究阶段, 难以达到实际应用的要求, 且有很多实 际应用方面的问题需要解决. 例如, 在生物传感器方面, 需进一步研究这些化合物的生物传感机理、寻找高效的 苂光能量转移体系, 并从多角度深入研究在基因水平上 的生命反应历程，以提高 TPE 衍生物在临床医学中的应 用; 在 OLED 发光器件方面, 目前应用于非掺杂 OLED 的高性能苂光发光层仍然很少, 因为大多数材料不具备 两个重要的先决条件, 即在固态时, 显示出高的发光效 率，同时具有良好的电荷输运性，所以今后对 TPE 衍生 物在 OLED 的应用研究重点仍需集中在提高材料发光 的饱和纯度、发光效率、材料对载流子的传输能力和延 长器件寿命等方面. 只有克服和突破 TPE 衍生物从实验 室研究到实际应用过程中碰到的种种难题, 方能把 TPE 衍生物的诸多特殊、优良性能体现于实际应用当中, 发 挥其潜在的应用价值.

综上所述, TPE 衍生物在化学传感、生物传感、有 机光电材料等诸多领域均有很好的应用前景, 通过国内 外科研工作者们不断地探索与突破, 必将开发出性能更 优良的 TPE 衍生物, 更好地在医疗、发光设备、环保等 领域造福人类.

\section{References}

[1] Friend, R. H.; Gymer, R. W.; Holmes, A. B; Burroughes, J. H.; Marks, R. N.; Taliani, C.; Bradley, D. D. C.; Santos, D. A. D.; Bredas, J. L.; Logdlund, M.; Salaneck, W. R. Nature 1999, 397, 121. 
[2] Cacialli, F.; Wilson, J. S.; Michels, J. J.; Daniel, C.; Silva, C.; Friend, R. H.; Severin, N.; Samori, P.; Rabe, J. P. O.; Connell, M. J.; Taylor, P. N.; Anderson, H. L. Nat. Mater. 2002, 1, 160.

[3] Toal, S. J.; Jones, K. A.; Magde, D.; Trogler, W. C. J. Am. Chem. Soc. 2005, 127, 11661.

[4] Luo, J. D.; Xie, Z. L.; Lam, J. W. Y.; Cheng, L. Chen, H. Y.; Qiu, C. F.; Kwok, H. S.; Zhan, X. W.; Liu, Y. Q.; Zhu, D. B.; Tang, B. Z. Chem. Commun. 2001, 1740.

[5] Tang, B. Z.; Zhan, X. W.; Yu, G.; Lee, P. P. S.; Liu, Y. Q.; Zhu, D. B. J. Mater Chem. 2001, 11, 2974.

[6] Song, M.; Chen, Z.; Yu, G. A.; Yi, J.; Liu, S. H. Chin. J. Org. Chem. 2015, 35, 681 (in Chinese). (宋敏, 陈钊, 余广鳌, 尹军, 刘盛华, 有机化学, 2015, 35, 681.)

[7] Qiu, S. H.; Xu, S. J.; Zhou, G. F.; Shui, L. L.; Zhu, X. Z. Chin. J. Org. Chem. 2015, 35, 1746 (in Chinese). (邱淑海, 许胜杰, 周国富, 水玲玲, 朱晓张, 有机化学, 2015, $35,1746$.

[8] Xie, Z. L.; Chen, C. J.; Xu, S. D.; Li, J.; Zhang, Y.; Liu, S. W.; Xu, J. R.; Chi, Z. G. Angew. Chem., Int. Ed. 2015, 54, 1.

[9] Xun, Z. Q.; Tang, H. Y.; Zeng, Y.; Chen, J. P.; Yu, T. J.; Zhang, X. H.; Li, Y. Acta Chim. Sinica 2015, 73, 819 (in Chinese). (寻知庆, 唐海云, 曾毅, 陈金平, 于天君, 张小辉, 李嫕, 化学 学报, 2015, 73, 819.)

[10] Mao, W. G.; Chen, K.; Ou, Y. M.; Xun, J. W.; Zhou, Y. B.; Wang, Y. S.; Song, Q. B.; Zhang, C. Chin. J. Org. Chem. 2015, 34, 161 (in Chinese).

(毛文纲, 陈康, 欧阳密, 孙璟玮, 周永兵, 王永胜, 宋庆宝, 张 诚, 有机化学, 2014, 34, 161.)

[11] Chen, S. J.; Hong, Y. N.; Zeng, Y.; Sun, Q. Q.; Liu, Y.; Zhao, E. G.; Bai, G. X.; Qu, J. N.; Hao, J. H.; Tang, B. Z. Chem. Eur. J. 2015, 21,1 .

[12] Guan, C. F.; Qian, Y. Chin. J. Org. Chem. 2014, 34, 537 (in Chinese).

(管成飞, 钱鹰, 有机化学, 2014, 34, 537.)

[13] Yuan, Y. Y.; Ryan T. K. K.; Tang, B. Z.; Liu, B. J. Am. Chem. Soc. 2014, 136, 2546.

[14] Xun, J. F.; Qian, Y. Chin. J. Org. Chem. 2016, 36, 151 (in Chinese). (孙京府, 钱鹰, 有机化学, 2016, 36, 151.)

[15] Petra, G.; Romana, C. K.; Maja V.; Boris, S. J. Am. Chem. Soc. 2014, 136, 7383.

[16] Niu, Y. F.; Qian, Y.; Hu, X. D. Chin. J. Org. Chem. 2016, 36, 555 (in Chinese).

(牛艳芳, 钱鹰, 胡秀东, 有机化学, 2016, 36, 555.)

[17] Wang, Z.; Yong T. Y.; Wan, J. S.; Li, J. H.; Zhao, H.; Zhao, Y. B.; Gan, L.; Yang, X. L.; Xu, H. B.; Zhang, C. T. ACS Appl. Mater. Interfaces 2015, 7, 3420.

[18] Wang, Z.; Yong, T. Y.; Wan, J. S.; Li, J. H.; Zhao, H.; Zhao, Y. B.; Gan, L. ACS Appl. Mater. Interfaces 2015, 7, 3420.

[19] He, Y. G.; Shi, S. U.; Liu, N.; Ding, Y. S.; Yin, J.; Wu, J. Q. Macromolecules 2016, 49, 48.

[20] Chen, L.; Jiang, Y.; Nie, H.; Hu, R. G.; Kwok, H. S.; Huang, F.; Qin, A. J.; Zhao, Z. J.; Tang, B. Z. ACS Appl. Mater. Interfaces 2014, 6, 17215.

[21] Zhang, W. J.; Kwok, R. T. K.; Chen, Y. L.; Chen, S. J.; Zhao, E. G.; Yu, C. Y. Y.; Lam, J. W. Y.; Zheng, Q. H.; Tang, B. Z. Chem. Commun. 2015, 51, 9022.

[22] Wang, H. B.; Liu, G. Y.; Gao, H. C.; Wang, Y. B. Polym. Chem. 2015, 6, 4715 .

[23] Zhang, X. Y.; Wang, K.; Liu, M. Y.; Zhang, X. Q; Tao, L.; Chen, Y. W.; Wei, Y. Nanoscale 2015, 7, 11486.

[24] Zhang, C. Q.; Li, Y. W.; Xue, X. D.; Chu, P. F.; Liu, C.; Yang, K.; Jiang, Y. G.; Chen, W. Q.; Zou, G. Z.; Liang, X. J. Chem. Commun.
2015, 51, 4168 .

[25] Liu, X. G.; Wang, H.; Chen, B.; Zou, Y.; Gu, Z. G.; Zhao, Z. J.; Shen, L. Chem. Commun. 2015, 51, 1677.

[26] Shen, W.; Yu, J. J.; Ge, J. Y.; Zhang, R. Y.; Cheng, F.; Li, X. F.; Fan, Y. Yu, S. A.; Liu, B.; Zhu, Q. ACS Appl. Mater. Interfaces 2016, 8, 927.

[27] He, Y. G.; Shi, S. Y.; Liu, N.; Ding, Y. S.; Yin, J.; Wu, J. Q. Macromolecules 2016, 49, 48.

[28] Li, S. H.; Shang, Y. L.; Zhao, E. G.; Kwok, R. T. K. Lam, J. W. Y.; Song, Y. L.; Tang, B. Z. J. Mater. Chem. C 2015, 3, 3445.

[29] Zhou, H.; Liu, F.; Wang, X. B.; Yan, H.; Song, J.; Ye, Q.;Tang, B. Z.; Xu, J. W. J. Mater. Chem. C 2015, 3, 5490.

[30] Dipratn, G. K.; Hrishikesh, J.; Mainak, B.; Mahesh, S. M.; Amrita, C. RSC Adv. 2014, 4, 47076.

[31] Zhang, L. F.; Hu, W. P.; Yu, L. P.; Wang, Y. Chem. Commun. 2015, $51,4298$.

[32] Li, Y.; Yu, H. J.; Shao, G.; Gan, F. A. Chemistry 2015, 301, 14

[33] Xu, H. B.; Wang, H. H.; Zhou, S. H.; Xiao, L. L.; Yan, Y.; Yuan, Q. Y. RSC, Adv. 2015, 5, 106061.

[34] Xu, H. R.; Li, K.; Wang, M. Q.; Wang, B. L.; Wang, X.; Yu, X. Q. Org. Chem. Front. 2014, 1,1276.

[35] Qin, A. J.; Lam, J. W. Y.; Tang, L.; Jim, C. K. W. Zhao, H.; Sun, J. Z.; Tang, B. Z. Macromolecules 2009, 42, 1421.

[36] Chan, C. Y. K.; Lam, J. W. Y.; Deng, C. M.; Chen, X. J.; Wong, K. S.; Tang, B. Z. Macromolecules 2015, 48, 1038.

[37] Dong, W. Y.; Fei, T.; Alex, P. C.; Ullrich, S. Polym. Chem. 2014, 5, 4048.

[38] Gao, M. X.; Wu, Y.; Chen, B.; He, B. R.; Nie, H.; Li, T. Y.; Wu, F. P.; Zhou, W. J.; Zhou, J.; Zhao, Z. J. Polym. Chem. 2015, 6, 7641.

[39] Xiang, K.; He, L. J.; Li, Y. M.; Xu, C. H.; Li, S. H. RSC Adv. 2015, $5,97224$.

[40] Zahn, S.; Swager, T. M. Angew. Chem., Int. Ed. 2002, 41,4225.

[41] Zhao, Z. J.; Guo, Y. J.; Jiang, T.; Chang, Z. F.; Lam, J. W. Y.; Xu, L. W.; Qiu, H. Y.; Tang, B. Z. Macromol. Rapid Commun. 2012, 33, 1074.

[42] Feng, H. T.; Zheng, Y. S. Chem. Eur. J. 2014, $20,195$.

[43] Wang, J. H.; Feng, H. T.; Zheng, Y. S. Chem. Commun. 2014, 50, 11407.

[44] Wang, J. H.; Ye, J. H.; Li, J.; Bai, Y.; Zhang, W. C.; He, W. J. RSC Adv. 2015, 5, 8912 .

[45] Zhang, C. Q.; Li, Y. W.; Xue, X. D.; Chu, P. F.; Liu, C.; Yang, K. N.; Jiang, Y. G.; Chen, W. Q.; Zou, G. Z.; Liang, X. Z. Chem. Commun. 2015, 51, 4168.

[46] Chen, S.; Hong, Y.; Liu, Y.; Liu, J.; Leung, C. W. T.; Li, M.; Kwok, R. T. K.; Zhao, E.; Lam, J. W. Y.; Yu, Y. J. Am. Chem. Soc. 2013, $135,4926$.

[47] Chen, S.; Liu, J.; Liu, Y.; Su, H.; Hong, Y.; Jim, C. K. W.; Kwok, R. T. K.; Zhao, N.; Qin, W.; Lam, J. W. Y. Chem. Sci. 2012, 3, 1804.

[48] Ma, Y.; Zeng, Y.; Liang, H.; Ho, C. L.; Zhao, C.; Huang, W.; Wong, W. Y. J. Mater. Chem. C 2015, 3, 11850.

[49] Dipratn, G.; Khandare, H. J.; Mainak, B.; Mahesh, S.; Majik; Amrita, C. Anal. Chem. 2015, 87, 10871.

[50] Lu, W.; Xiao, P.; Gu, J. C.; Zhang, J. W.; Huang, Y. Z.; Huang, Q.; Chen, T. Sensors Actuators B 2016, 228, 551.

[51] Li, T. Z.; He, S. C.; Qu, J. N.; Wu, H.; Wu, S. Z.; Zhao, Z. J.; Qin, A. J.; Hu, R. R.; Tang, B. Z. J. Mater. Chem. C 2016, 4, 2964.

[52] Li, J.; Zhang, Y.; Mei, J.; Jacky, W. Y. L.; Hao, J. H.; Tang, B. Z. Chem. Eur. J. 2015, 21, 907.

[53] Zhang, R. Y.; Ryan, T. K.; Tang, B. Z.; Liu, B. RSC Adv. 2015, 5, 28332.

[54] Shi, H. B.; Ryan, T. K.; Liu, J. Z.; Xing, B. G.; Tang, B. Z.; Liu, B. J. Am. Chem. Soc. 2012, 134, 17972. 
[55] (a) Pratley, R. E.; Salsali, A. Curr. Med. Res. Opin. 2007, 23, 919. (b) Lovshin, J. A.; Drucker, D. J. Nat. Rev. Endocrinol. 2009, 5, 262.

[56] Mulvihill, E. E.; Drucker, D. J. Endocrinol. Rev. 2014, 35, 992.

[57] (a) Herman, G. A.; Bergman, A.; Stevens, C.; Kotey, P.; Yi, B.; Zhao, P.; Dietrich, B.; Golor, G.; Schrodter, A.; Keymeulen, B.; Lasseter, K. C.; Kipnes, M. S.; Snyder, K.; Hilliard, D.; Tanen, M.; Cilissen, C.; De Smet, M.; Lepeleire, I.; Van Dyck, K.; Wang, A. Q.; Zeng, W.; Davies, M. J.; Tanaka, W.; Holst, J. J.; Deacon, C. F.; Gottesdiener, K. M.; Wagner, J. A.; Clin, J. Endocrinol. Metab. 2006, $91,4612$.

(b) Inagaki, N.; Onouchi, H.; Maezawa, H.; Kuroda, S.; Kaku, K. Lancet Diabetes Endocrinol. 2015, 3, 191.

[58] Wang, Y.; Wu, X. L.; Cheng, Y. Y.; Zhao, X. P. Chem. Commun. 2016, 52,3478 .

[59] Zhang, S. Y.; Ong, C. N.; Shen, H. M. Cancer Lett. 2004, 208(2), 143.

[60] Lou, X. D.; Zhao, Z. J.; Hong, Y. N.; Dong, C.; Min, X. H.; Zhuang, Y.; Xu, X. M.; Jia, Y. M. Xia, F.; Tang, B. Z. Nanoscale 2014, 6, 14691.

[61] Yuan, Y. Y.; Ryan T. K.; Kwok.; Feng, G. X.; Liang, J.; Geng, G. L.; Tang, B. Z.; Liu, B. Chem. Commun. 2014, 50, 295.

[62] D'Autreaux, B.; Toledano, M. B. Nat. Rev. Mol. Cell Biol. 2007, 8, 813.

[63] Weinstain, R.; Savariar, E. N.; Felsen, C. N.; Tsien, R. Y. J. Am. Chem. Soc. 2014, 136, 874.

[64] Zhang, W.; Liu, W.; Li, P.; Huang, F.; Wang, H.; Tang, B. Anal. Chem. 2015, 87, 9825.

[65] Yang, Z.; Yuan, Y.; Jiang, R.; Fu, N.; Lu, X.; Tian, C.; Hu, W.; Fan, Q.; Huang, W. Polym. Chem. 2014, 5, 1372.

[66] Liu, M.; Zhang, X.; Yang, B.; Deng, F.; Li, Z.; Wei, J.; Zhang, X.; Wei, Y. Appl. Surf. Sci. 2014, 322, 155.

[67] Zhang,Y.; Wang, X. J.; Guo, M.; Yan, H. S.; Wang, C. H.; Liu, K. L. Chin. J. Polym. Sci. 2014, 32, 1329.

[68] Huang, Z.; Zhang, X.; Zhang, X.; Fu, C.; Wang, K.; Yuan, J.; Tao, L.; Wei, Y. Polym. Chem. 2015, 6, 607.

[69] Yuan, Y.; Kwok, R. T.; Feng, G.; Liang, J.; Geng, J.; Tang, B. Z.; Liu, B. Chem. Commun. 2014, 50, 295.

[70] Gao, M.; Hu, Q.; Feng, G.; Tang, B. Z. Liu, B. J. Mater. Chem. B 2014, 2, 3438.

[71] Huang, Z.; Zhang, X.; Zhang, X.; Yang, B.; Zhang, Y.; Wang, K.; Yuan, J.; Tao, L.; Wei, Y. Polym. Chem. 2015, 6, 2133.

[72] Wang, K.; Zhang, X.; Zhang, X.; Yang, B.; Li, Z.; Zhang, Q.; Huang, Z.; Wei, Y. J. Mater. Chem. C 2015, 3, 1854.

[73] Zhang, X.; Zhang, X.; Wang, K.; Liu, H.; Gu, Z.; Yang, Y.; Wei, Y. J. Mater. Chem. C 2015, 3, 1738.

[74] Wang, K.; Zhang, X.; Zhang, X.; Yang, B. Li, Z.; Zhang, Q.; Huang, Z.; Wei, Y. Polym. Chem. 2015, 6, 1360.

[75] Li, H. Y.; Chang, J. F.; Hou, T.; Li, F. J. Mater. Chem. B 2016, 4, 198.
[76] Chen, Y. L.; Li, M.; Hong, Y. N.; Jacky; Lam, W. Y.; Zheng, Q. C.; Tang, B. Z. ACS Appl. Mater. Interfaces 2014, 6, 10783.

[77] Yu, G. C.; Tang, G. P.; Huang, F. J. Mater. Chem. C 2014, 2, 6609.

[78] Chen, L.; Jiang, Y. B.; Nie, H.; Hu, R. G.; Kwok, H. S.; Huang, F.; Qin, A. G.; Zhao, Z. J.; Tang, B. Z. ACS Appl. Mater. Interfaces 2014, 6, 17215.

[79] Yang, J.; Sun, N.; Huang, J.; Li, Q.; Peng, Q.; Tang, X.; Dong, Y.; Ma, D.; Li, Z. J. Mater. Chem. C 2015, 3, 2624.

[80] Shi, H. P.; Xin, D. H.; Gu, X. G.; Zhang, P. F.; Peng, H. R.; Chen, S. M.; Lin, G. W.; Zhao, Z. J.; Tang, B. Z. J. Mater. Chem. C 2016, 4, 1228.

[81] Chen, L.; Zhang, C. Y.; Lin, G. W.; Nie, H.; Luo, W. W.; Zhuang, Z. Y.; Ding, S. Y.; Hu, R. G.; Su, S. J.; Huang, F.; Qin, A. G.; Zhao, Z. J.; Tang, B. Z. J. Mater. Chem. C 2016, 4, 2775.

[82] Tang, F.; Peng, J.; Liu, R.; Yao, C.; Xu, X.; Li, L. RSC. Adv. 2015, 5,71419 .

[83] Kamtekar, K. T.; Wang, C.; Bettington, S.; Batsanov, A. S.; Perepichka, I. F.; Bryce, M. R.; Ahn, J. H.; Rabinal, M.; Petty, M. C. J. Mater. Chem. 2006, 16, 3823.

[84] Zhang, X. W.; Wang, J.-Y.; Zhao, L. L.; Guo, X.; Lai, W. Y.; Huang, W. Chin. Phys. Lett. 2013, 30, 98501.

[85] Jiang, Z. Q.; Ye, T. L.; Yang, C. L.; Yang, D. Z.; Zhu, M. R.; Zhong, C.; Qin, J. G.; Ma, D. G. Chem. Mater 2011, 23, 771.

[86] Huang, J.; Jiang, Y. B.; Yang, J.; Tang, R.; Xie, N.; Li, Q. Q.; Kwok, H. S.; Tang, B. Z.; Li, J. J. Mater. Chem. C 2015, 2, 2028.

[87] Zhao, Z. J.; Jacky, W. Y. L.; Carrie, Y. K. C.; Chen, S. M.; Liu, J. Z.; Lu, P.; Mario R.; Maldonado, J. L.; Gabriel, R. O.; Herman, H. Y. S.; Williams, L. D.; Su, H. M.; Wong, K. S.; Ma, Y. G.; Kwok, H. S.; Qiu, H. Y.; Tang, B. Z. Adv. Mater 2011, 23, 5430.

[88] Li, Y. L.; Li, Z. P.; Tursunjan, A.; Ren, T. H.; Dong, W. J. Phys. Chem. Chem. Phys. 2014, 16, 26193.

[89] Danos, L.; Parel, T.; Markvart, T.; Barrioz, V.; Brooks, W. S. M.; Irvine, S. J. C. Sol. Energy Mater. Sol. Cells 2012, 98, 486.

[90] Richards, B. S.; McIntosh, K. R. Prog. Photovol. 2007, 15, 27.

[91] Ross, D.; Klampaftis, E.; Fritsche, J.; Bauer, M.; Richards, B. S. Sol. Energy Mater. Sol. Cells 2012, 103, 11.

[92] Trungkathan, S.; Polpanich, D.; Smanmoo, S.; Tangboriboonrat, P. J. Appl. Polym. Sci. 2015, 131, 40012 (1-9).

[93] Zhao, L.; Chen, Y. F.; Yuan, J.; Chen, M. H.; Zhang, H.; Li, X. H. ACS. Appl. Mater. Interfaces 2015, 7, 5177.

[94] Zhao, E. G.; Chen, Y. L.; Wang, H.; Chen, S. J.; Jacky, W. Y. L.; Chris, W. T. L.; Hong, Y. N.; Tang, B. Z. ACS Appl. Mater. Interfaces 2015, 7, 7180 .

[95] Chen, L.; Wang, Y. H.; He, B. R.; Nie, H.; Hu, R. R.; Huang, F.; Qin, A. J.; Zhou, X. S.; Zhao, Z. J.; Tang, B. Z. Angew. Chem. 2015, 127, 4305.

[96] Zhao, Z. J.; Li, Z. F.; Jacky W. Y. L.; Maldonado, J. L.; Gabriel, R. O.; Liu, Y.; Yuan, W. Z.; Xu, J. B.; Miao, Q.; Tang, B. Z. Chem. Commun. 2011, 47, 6924. 